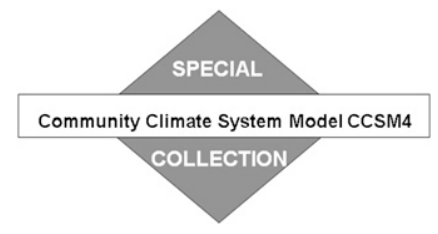

\title{
Improved Sea Ice Shortwave Radiation Physics in CCSM4: The Impact of Melt Ponds and Aerosols on Arctic Sea Ice*
}

\author{
Marika M. Holland, David A. Bailey, And Bruce P. Briegleb \\ National Center for Atmospheric Research, ${ }^{+}$Boulder, Colorado \\ BONNIE LIGHT \\ University of Washington, Seattle, Washington \\ ELIZABETH HunKE \\ Los Alamos National Laboratory, Los Alamos, New Mexico
}

(Manuscript received 3 February 2011, in final form 1 July 2011)

\begin{abstract}
The Community Climate System Model, version 4 has revisions across all components. For sea ice, the most notable improvements are the incorporation of a new shortwave radiative transfer scheme and the capabilities that this enables. This scheme uses inherent optical properties to define scattering and absorption characteristics of snow, ice, and included shortwave absorbers and explicitly allows for melt ponds and aerosols. The deposition and cycling of aerosols in sea ice is now included, and a new parameterization derives ponded water from the surface meltwater flux. Taken together, this provides a more sophisticated, accurate, and complete treatment of sea ice radiative transfer. In preindustrial $\mathrm{CO}_{2}$ simulations, the radiative impact of ponds and aerosols on Arctic sea ice is $1.1 \mathrm{~W} \mathrm{~m}^{-2}$ annually, with aerosols accounting for up to $8 \mathrm{~W} \mathrm{~m}^{-2}$ of enhanced June shortwave absorption in the Barents and Kara Seas and with ponds accounting for over $10 \mathrm{~W} \mathrm{~m}^{-2}$ in shelf regions in July. In double $\mathrm{CO}_{2}\left(2 \mathrm{XCO}_{2}\right)$ simulations with the same aerosol deposition, ponds have a larger effect, whereas aerosol effects are reduced, thereby modifying the surface albedo feedback. Although the direct forcing is modest, because aerosols and ponds influence the albedo, the response is amplified. In simulations with no ponds or aerosols in sea ice, the Arctic ice is over $1 \mathrm{~m}$ thicker and retains more summer ice cover. Diagnosis of a twentieth-century simulation indicates an increased radiative forcing from aerosols and melt ponds, which could play a role in twentieth-century Arctic sea ice reductions. In contrast, ponds and aerosol deposition have little effect on Antarctic sea ice for all climates considered.
\end{abstract}

\section{Introduction}

Sea ice is a sensitive indicator of climate change and reductions in Arctic ice cover have been considerable over the satellite record since 1979 (e.g., Serreze et al. 2007).

\footnotetext{
* Supplemental information related to this paper is available at the Journals Online Web site: http://dx.doi.org/10.1175/JCLI-D-1100078.s1.

+ The National Center for Atmospheric Research is sponsored by the National Science Foundation.
}

Corresponding author address: Marika M. Holland, 1850 Table Mesa Drive, Boulder, CO 80305.

E-mail: mholland@ucar.edu
Climate models project that Arctic sea ice loss will continue into the future with the possibility of ice-free summers occurring within this century (e.g., Holland et al. 2006; Wang and Overland 2009; Boe et al. 2009). Accompanying this rapid sea ice loss is an amplified warming in Arctic regions (e.g., Holland and Bitz 2003) that results in part from the surface albedo feedback. With the loss of high-albedo sea ice and resulting exposure of the dark ocean surface, more sunlight is absorbed, enhancing surface warming, which is then released back to the atmosphere in the fall-winter (Manabe and Stouffer 1980). This feedback plays a dominant role in the Arctic amplification of global warming (e.g., Hall 2004).

Climate model simulations have provided considerable insight on sea ice relevant feedbacks and processes (e.g., 
Solomon et al. 2007). These models have traditionally used a sea ice surface albedo parameterization that depends on properties of the surface state, including the presence of snow cover, the thickness of snow and ice, and the surface temperature (e.g., Briegleb et al. 2004). Although these parameterizations have generally increased in complexity, they are still based on empirical relationships and do not explicitly represent the physics of scattering and absorption by snow and ice particles. As discussed by Curry et al. (2001), although different albedo parameterizations can be tuned to provide a reasonable mean climate state, they may differ considerably in their response to a forcing perturbation and simulated surface albedo feedback strength. Given that this feedback plays a dominant role in simulated high northern latitude-amplified warming (e.g., Hall 2004), it is imperative that more physically based parameterizations are developed to simulate the surface albedo evolution. Additionally, parameterizations that are able to simulate shortwave scattering and absorption resulting from absorbers within the sea ice, such as black carbon and dust, are required if we are to gain a better understanding of the role of these forcings on climate (e.g., Flanner et al. 2007).

As discussed by Perovich et al. (2002a), the seasonal evolution of Arctic sea ice albedo undergoes a number of distinct phases including dry snow, melting snow, pond formation, pond evolution, and fall freeze-up. Accounting for these phases in numerical models requires a parameterization of melt pond effects. Melt ponds are primarily formed by the accumulation of surface meltwater from snow and ice. Their shape, size, and coverage are determined by a number of factors including the total amount of water available and the ice surface topography. Several field experiments in combination with satellite observations have provided information on the characteristics of Arctic melt ponds (e.g., Tschudi et al. 2008, 2001; Yackel and Barber 2000; Fetterer and Untersteiner 1998). Perhaps the most detailed assessment of melt pond evolution over the summer occurred during the Surface Heat Budget of the Arctic (SHEBA) experiment (Perovich et al. 2002a). In contrast to the Arctic, sea ice in the Southern Hemisphere has essentially no pond coverage (e.g., Andreas and Ackley 1982).

In addition to the influence of changing physical sea ice and snow properties on surface albedo, it is possible for "external absorbers" to be incorporated into the snow-ice system. In particular, deposition of aerosols (black carbon and dust) from the atmosphere can darken the surface and enhance absorption. Because both the deposition and melt out of aerosols vary over time, this can influence sea ice variability. A number of studies have investigated the effects of black carbon deposition on snow and sea ice (e.g., Hansen and Nazarenko 2004; Flanner et al. 2007,
2009) and show that this forcing is effective at driving variations in climate because it excites the surface albedo feedback.

Here we document new radiative transfer aspects of the sea ice model component of the Community Climate System Model, version 4 (CCSM4) and assess their influence on the climate and climate response of CCSM4. The improvements include a multiple scattering calculation with inherent optical properties (IOPs) for ice and snow based on physical measurements (Briegleb and Light 2007, hereafter BL07); a melt pond parameterization that relates the evolution of pond area and depth to the surface meltwater flux; and the deposition, cycling, and radiative impacts of aerosols on sea ice. These improvements allow for an internally consistent and physically based treatment of sea ice shortwave radiation physics in a coupled climate model, which represents an important step forward in the realism of these processes. Using constrained model experiments, we consider whether this increased realism alters climate feedbacks and modifies the climate system response to $\mathrm{CO}_{2}$ forcing perturbations.

\section{Model description}

The sea ice component of CCSM4 uses the Los Alamos National Laboratory sea ice model, version 4 (CICE4) as the base code (Hunke and Lipscomb 2008). This model includes elastic-viscous-plastic dynamics (Hunke and Dukowicz 2002), energy-conserving thermodynamics (Bitz and Lipscomb 1999), and a subgridscale ice thickness distribution (ITD; Thorndike et al. 1975). The ITD includes five categories within each grid cell, which have different thickness (within a prescribed range), different surface properties, and different melt and growth rates as computed by the thermodynamics. Mechanical deformation (ridging and rafting) follows Rothrock (1975), using a modified expression for the participation function (Lipscomb et al. 2007). A twodimensional, linear incremental remapping algorithm (Lipscomb and Hunke 2004) is used for advection. A similar, one-dimensional linear remapping scheme (Lipscomb 2001) transfers ice among ITD categories as needed because of thermodynamic, ridging, and advective ice thickness changes. In general, the physical parameterizations in the CCSM3 and CCSM4 ice components are quite similar. Major changes in the CCSM4 ice model include a new radiative transfer scheme, melt ponds and aerosols (all discussed below), a nonzero heat capacity snow cover, and an altered atmospheric boundary layer description that allows sensible heat transfer at the surface even when winds are calm (Jordan et al. 1999). Mechanical redistribution also changed in two ways: the ratio of new ridge height to ridged ice area decreased, and $50 \%$ of 
the snow volume is now deposited in the ocean during the ridging process (whereas in CCSM3 all of the snow remained on the sea ice during ridging). The CCSM4 sea ice component is thoroughly documented in Hunke and Lipscomb (2008).

\section{a. Shortwave radiation parameterization}

A fundamental improvement in the new sea ice component is the incorporation of a new radiative transfer scheme for the treatment of solar radiation (BL07; see also the supplemental material for further details). This scheme calculates multiple scattering of solar radiation in sea ice using a delta-Eddington approximation with inherent (i.e., microscopic) optical properties that specify scattering-absorption properties for snow, sea ice, ponds, and included absorbers. Thus, it uses IOPs to compute apparent (i.e., macroscopic) optical properties (e.g., albedo, transmittance, and total energy absorbed). This permits bulk properties, such as the surface albedo, to accurately represent changes in the IOPs and the incident radiation field. This is in contrast to previous versions of CCSM (CCSM3; Briegleb et al. 2004) and nearly all other sea ice models used in coupled climate systems (Solomon et al. 2007), which instead directly parameterize the albedo using bulk sea ice properties (e.g., snow and ice thickness, surface temperature, etc.).

The CCSM4 atmosphere provides shortwave fluxes for direct-diffuse radiation in two spectral bands: $0.2-0.7 \mu \mathrm{m}$ and $0.7-5.0 \mu \mathrm{m}$. The CCSM4 sea ice radiation scheme subdivides the near-infrared band into two subbands, 0.7 $1.19 \mu \mathrm{m}$ and 1.19-5.00 $\mu \mathrm{m}$, to better represent radiation penetration through thin snow and sea ice. It also distinguishes direct from diffusely scattered radiation.

The native vertical structure of the CCSM4 sea ice component is one snow layer (if present) overlying four equal-thickness sea ice layers. The CCSM4 radiation scheme subdivides the snow layer and the top sea ice layer into a surface scattering layer (SSL) and the remaining original top layer. An explicit pond over sea ice is allowed for ponded ice. Thus, for each ice thickness category in the ice-covered portion of a grid cell, three surface types are allowed, snow covered ice, bare ice, and ponded ice, with horizontal fractions (normalized to one) of $f_{s}, f_{i}$, and $f_{p}$, respectively (Fig. 1). (Note that a separate open water fraction is also possible within a grid cell, but for simplicity the following description refers to the ice-covered fraction.) The snow fraction is one for snow depths larger than $0.03 \mathrm{~m}$ and proportional to snow thickness for smaller depths to account for patchy conditions over uneven surface topography (Brandt et al. 2005). Pond fraction is determined by the melt pond parameterization as discussed below. Bare sea ice fraction is evaluated using the normalization condition.

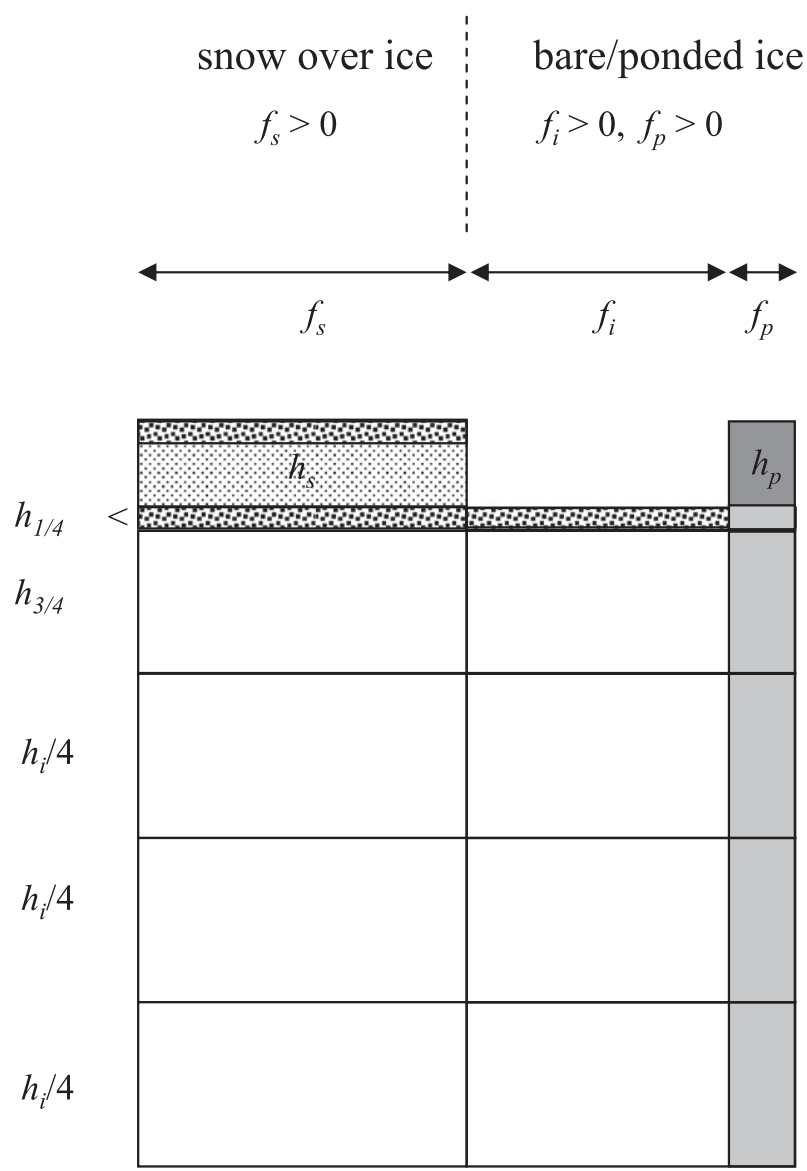

FIG. 1. Types of snow-sea ice-pond surfaces used in the shortwave radiation treatment, along with the vertical layering for these surfaces. The surfaces include snow of depth $h_{s}$ with fractional coverage $f_{s}$, bare sea ice with fractional coverage $f_{i}$ and thickness $h_{i}$, and ponded sea ice with fractional coverage $f_{p}$ and ponds of depth $h_{p}$. The sea ice SSL thickness is $h_{1 / 4}$, and the drained layer thickness just below the SSL is $h_{3 / 4}$. Snow and sea ice SSL are stippled with large dots; the snow under its SSL is lightly stippled. Sea ice under pond is colored light gray, whereas pond is colored dark gray. Vertical dimensions are to relative scale for $h_{i}=1.2 \mathrm{~m}, h_{s}=0.15 \mathrm{~m}$, and $h_{p}=0.15 \mathrm{~m}$, with both snow and sea ice SSL $0.04 \mathrm{~m}$ thick.

The SSL, which is assumed to be present at all times (Perovich et al. 2002a), accounts for the highly scattering properties of surface bare sea ice and under-pond sea ice, though the snow SSL has the same optical properties as the remaining snow layer. Absorption in the SSL is considered surface absorption for the thermodynamics (pond absorption is included for ponded ice). For thick snow and sea ice, the SSLs are specified to be 0.04 and $0.05 \mathrm{~m}$ thick, respectively. When snow is thinner than $0.08 \mathrm{~m}$, the snow SSL is half the snow thickness. For ice thinner than $1.5 \mathrm{~m}$, ice SSL thickness is set to $h_{i} / 30$, where $h_{i}$ is sea ice thickness, or about one-third freeboard. This results in surface albedos in good agreement with available observations as sea ice thickness decreases from 
$1.5 \mathrm{~m}$ down to $0.01 \mathrm{~m}$. Broadband surface albedos with overcast sky for thin sea ice range from 0.10 (0.01-m ice thickness) to 0.25 (0.10-m ice thickness) to 0.4 (0.30-m ice thickness). These are within 0.02 of the observation curve fit of Brandt et al. (2005) (see also supplemental material) and within the scatter of observations listed in BL07.

Snow and sea ice SSLs are considered to be granular, but, below the ice SSL and at the pond surface, refraction must be considered. This refraction is represented by adding a refractive layer at the bottom of the sea ice SSL and at the top of the pond. Compared to benchmark radiation calculations (BL07), sea ice wave band albedos using this refraction approximation are within 0.02 and the broadband albedos are within 0.01 .

For each surface type, layer reflectivities and transmissivities are evaluated using the delta-Eddington approximation, assuming each layer is homogenous. Layers are then vertically combined to represent multiple scattering over all layers, assuming interlayer scattered radiation is diffuse. For each of the five categories in the sea ice component, the scheme calculates albedos, internal absorption, and transmission to the underlying ocean for the fractions of snow-covered sea ice, bare sea ice, and ponded sea ice separately. These are then horizontally aggregated such that the final surface albedos $\alpha$ and radiative fluxes $F$ for the wave bands are

$$
\begin{aligned}
& \alpha_{i} f_{i}+\alpha_{s} f_{s}+\alpha_{p} f_{p}=\alpha \quad \text { and } \\
& F_{i} f_{i}+F_{s} f_{s}+F_{p} f_{p}=F,
\end{aligned}
$$

with

$$
f_{i}+f_{s}+f_{p}=1
$$

The inherent optical properties of snow are taken from the usual equivalent ice sphere approximation (see Grenfell and Warren 1999; BL07) for specified snow grain radii. Fresh snow grain radius is set to $125 \mu \mathrm{m}$, melting snow grain radii to $1500 \mu \mathrm{m}$, with a linear interpolation in surface temperature between them from $-1.5^{\circ}$ to $0^{\circ} \mathrm{C}$. Bare and ponded ice IOPs are taken from semiempirical modeling based on SHEBA observations (BL07; Light et al. 2008). For pond depths less than $0.005 \mathrm{~m}$, bare ice IOPs are used; for pond depths greater than $0.20 \mathrm{~m}$, the ponded ice IOPS are used. To allow for the transition from bare to ponded ice of pond depths between 0.01 and $0.20 \mathrm{~m}$, bare ice and pond scattering IOPs are weighted by pond depth, resulting in a mostly smooth transition from high bare ice albedos (around 0.65) to much lower ponded albedos (around 0.21 for pond depth of $0.20 \mathrm{~m}$ ). Although sea ice IOPs were taken from SHEBA data in the Arctic, they should still be applicable to Antarctic sea ice. In particular, we compared band albedos for thick snow over sea ice with
Antarctic measurements (Brandt et al. 2005), and, despite uncertainties in the snow grain radii during the measurements, agreement within $0.02-0.04$ absolute for snow grain radii ranging from 100 to $500 \mu \mathrm{m}$ was obtained, including change in near-infrared albedo between clear to cloudy sky conditions (see supplemental material). Aerosol inherent optical properties are taken from the CCSM4 land component (Oleson et al. 2010), where the near-infrared spectral bands are averaged from four to two (M. Flanner 2010, personal communication; see supplemental material). Black carbon and dust aerosols are used here.

Overall, this scheme results in albedos, internal absorption, and transmission in good agreement with available benchmark calculations and observations (BL07). Spectral and broadband surface albedos for thick snow over sea ice and bare sea ice agree within 0.02 of benchmark calculations and agree for bare ice with the mean SHEBA albedos to within 0.002 by construction. Included absorbers such as aerosols are added by assuming homogeneous mixing in each layer, thus aggregating inherent optical properties of aerosols and snow-ice for each vertical layer. The more physically based treatment of radiation physics allows a physically consistent incorporation of the radiative effects of melt ponds and included absorbers. Note that sea ice albedo tuning is possible through the adjustment of the IOPs for snow, sea ice, and melt ponds. The model contains parameters that are formulated in terms of standard deviation from limited observations for this purpose.

\section{b. Melt pond parameterization}

The melt pond parameterization used here relates the pond water volume to surface meltwater fluxes. This builds on single-column modeling work (e.g., Ebert and Curry 1993; Schramm et al. 1997). Recently, Pedersen et al. (2009) documented the effects of similarly parameterized melt ponds on the simulated sea ice of the ECHAM5 general circulation model. The parameterization used here is quite simple and only influences the sea ice radiation. The freshwater flux to the ocean is not affected, and no refreezing (and latent heat release) from the ponds occurs. More sophisticated melt pond models are under development (Flocco and Feltham 2007; Flocco et al. 2010; Skyllingstad and Paulson 2007), but these have not yet been used within fully coupled models. In contrast to previous work where empirical relationships were used to derive a surface albedo from pond characteristics, the parameterization used here interacts with the sophisticated radiative transfer calculation described above to simulate the absorption and scattering associated with the different surface types.

Given that CCSM4 incorporates a subgrid-scale ice thickness distribution, melt pond properties are computed 
for each of the five ice categories. A linear fit to the observed SHEBA time evolution of pond fraction and depth (Perovich et al. 2003) is used to relate pond depth $h_{p}$ in meters to the fraction of ice covered by melt ponds $f_{p}$ with the constraint that pond depth is limited to be less than $90 \%$ of the category ice thickness $h_{i}$,

$$
h_{p}=\min \left(0.8 f_{p}, 0.9 h_{i}\right) \text {. }
$$

By using this linear fit and defining a quantity called the melt pond volume $V_{\text {pond }}$ (volume per unit area of sea ice),

$$
V_{\text {pond }}=f_{p} h_{p},
$$

we form the basis of a parameterization of ponds.

Let $r$ be the fraction of surface meltwater and rainfall that runs off the surface of the ice. We assume that $r$ varies with the total ice fraction $A$ in a grid cell as

$$
r=0.85-0.7 A .
$$

This results in the same runoff fraction $r$ for each ice category within a grid cell. Because $0<A<1$, at least $15 \%$ and no more than $85 \%$ of the meltwater runs off and grid cells with very little ice cover (and hence more open water area) have a higher runoff fraction to represent the greater proximity of ice to open water. There is little observational information to constrain $r$, allowing it to be used as a tuning parameter.

The remaining $(1-r)$ fraction of the surface meltwater and rainfall collects in ponds and is accumulated in a virtual reservoir that is the melt pond volume $V_{\text {pond }}$,

$$
\rho_{w} \frac{d V_{\text {pond }}}{d t}=(1-r)\left[\frac{d h_{\text {top }}}{d t} \rho_{i}+\frac{d h_{s}}{d t} \rho_{s}+F_{\text {rain }}\right] \text {, }
$$

where $d h_{\text {top }} / d t$ is the surface ice melt rate; $d h_{s} / d t$ is the snowmelt rate; $\rho_{w}, \rho_{i}$, and $\rho_{s}$ are the densities of water, ice, and snow, respectively; and $F_{\text {rain }}$ is the rainfall flux in $\mathrm{kg} \mathrm{m}^{-2} \mathrm{~s}^{-1}$.

Once we have accumulated the meltwater in the pond volume $V_{\text {pond }}$, we solve for melt pond fraction $f_{p}$ by combining (2) and (3). The pond depth is then computed using (2).

Meltwater accumulation starts even before the snow has completely disappeared from an ice category. The melt ponds are not allowed to show through the snow-covered portion of the ice category but are allowed to change the surface albedo in the bare ice portion. Therefore, the pond fraction is simply reduced by the fraction of snow cover in an ice category. Finally, the ponds are removed when the ice drops below 0.1-m thickness (i.e., we assume that ponds for such thin ice will completely run off). Because the pond fractions are small and the albedos are low for such thin ice, this only causes a small (0.01-0.02) surface albedo change.

For cold conditions (primarily during the autumn freezeup), a simple exponential function of the air temperature is used to reduce the melt pond volume,

$$
V_{\text {pond }}^{i+1}=V_{\text {pond }}^{i} e^{0.01\left(d T_{s}-2\right) /\left(T_{\text {melt }}-2\right)} \text {, }
$$

where the superscript $i$ represents the time step, $d T_{s}$ is the surface temperature difference from melting $\left(T_{\text {melt }}-\right.$ $T_{\text {sfc }}$ ), and $T_{\text {melt }}$ is the melting temperature for sea ice (set to $0^{\circ} \mathrm{C}$ ). The equation is invoked whenever surface temperature $T_{\text {sfc }}$ drops below $-2^{\circ} \mathrm{C}$ and allows the ponds to rapidly disappear as the autumn freeze-up progresses. The pond volume reduction leads to a reduced pond fraction. Also, as snow falls and accumulates on the ice, the snow fraction increases rapidly decreasing the pond fraction.

Currently, the melt pond volume is considered a virtual reservoir of water and the flux of meltwater to the ocean is not modified. Instead, this parameterization only affects the albedo calculation and no latent heat effects due to pond refreezing are considered. A pond area fraction and depth are calculated for each of the five ice categories resolved in the model. As the ice area shifts within the ITD because of ice growth, melt, and mechanical redistribution, the pond characteristics per category are modified accordingly following

$$
\frac{d V_{\text {pond }_{n}}}{d t}=\frac{\partial}{\partial h}\left(g_{n} V_{\text {pond }_{n}}\right)+\Phi_{p},
$$

where $n$ denotes the ice category, $g$ is the net ice growth rate, and $\Phi_{p}$ is the redistribution of ponds among ice categories due to ridging. Additionally, for each ice category $n$, with fractional area $a_{n}$, the pond volume is advected with the single ice motion vector $\mathbf{u}$ that is computed per grid cell and is treated as an ice area-weighted passive tracer,

$$
\frac{d\left(a_{n} V_{\text {pond }_{n}}\right)}{d t}=-\nabla \cdot\left(a_{n} V_{\text {pond }_{n}} \mathbf{u}\right) .
$$

In CCSM3, the sea ice model included an implicit melt pond assumption in which the albedo was adjusted based on the surface temperature using "warm" and "cold" bare ice albedo values. This assumed a constant pond albedo, bare ice albedo, and ponded areal fraction whenever melting bare ice was present. The new explicit melt pond formulation that depends on surface meltwater allows for changing pond conditions for different ice types and/or climate regimes, with implications for the surface albedo feedback. Using stand-alone sea ice simulations forced by 
historical observations, Flocco et al. (2010) compared an earlier (and quite similar) implementation of the CCSM4 melt pond scheme with a more sophisticated model that included the effects of ice permeability, ice topography, and refreezing. This comparison showed that both pond schemes had a similar influence on ice state characteristics, suggesting that a simple scheme such as that used here reasonably represents the first-order effects of melt ponds.

\section{c. Aerosol parameterization}

The aerosol cycling included here is based on previous work (Flanner et al. 2007) but accounts for sea ice advective and ridging effects because it is incorporated in a dynamic-thermodynamic sea ice model. After deposition, vertical migration of aerosols in the ice and overlying snowpack can occur in response to sea ice melt and growth and snow accumulation. The aerosol content is also transported laterally with the sea ice motion. We allow two layers of aerosol content in the snowpack and two in the underlying sea ice. The upper layers in snow and ice correspond to the SSLs used in the radiative transfer. The aerosol content is assumed to be well mixed within each layer. Three different aerosol types are included: hydrophobic black carbon, hydrophilic black carbon, and a single dust category (Table 1).

Flanner et al. (2007) computed aerosol mass content $m$ changes for terrestrial snow cover using

$$
\frac{d m_{i}}{d t}=S\left(\eta_{i+1} m_{\mathrm{ri}+1}-\eta_{i} m_{\mathrm{ri}}\right)+D
$$

where $S$ is the scavenging ratio; $\eta_{i}$ is the mass flux of water out of layer $i ; m_{\mathrm{ri}}$ is the mass mixing ratio of the aerosol in layer $i$ (aerosol mass divided by liquid plus solid $\mathrm{H}_{2} \mathrm{O}$ mass); and $D$ is the atmospheric deposition, which is added only to the surface layer.

In the model used here, liquid meltwater is not retained in the ice or overlying snowpack (although brine volumes are implicit in the thermodynamics; Bitz and Lipscomb 1999). Therefore, ice melt fluxes water and all or some of the contained aerosol into the ocean. This results in an aerosol mass content $m$ change for layer $i$ of the snow or sea ice following

$$
\frac{d m_{i}}{d t}=-S g_{\text {sfc }_{i}} m_{\mathrm{ri}}-g_{\text {base }_{i}} m_{\mathrm{ri}}-g_{\mathrm{lat}_{i}} m_{\mathrm{ri}}+D,
$$

where $g_{\text {sfc }_{i}}, g_{\text {base }_{i}}$, and $g_{\text {lat }}$ are the top surface, basal, and lateral melting rates in mass of water per second that affect layer $i$. The surface melt rate $g_{\text {sfc }}$ includes surface snowmelt or surface ice melt when the ice is snow free. Surface and lateral melting can modify the aerosol content in both the sea ice and its overlying snow cover (when present), whereas basal melting only affects the
TABLE 1. The scavenging factors used for different aerosols, following Flanner et al. (2007).

\begin{tabular}{lc}
\hline \hline \multicolumn{1}{c}{ Aerosol type } & Scavenging factor $(S)$ \\
\hline Hydrophobic black carbon & 0.03 \\
Hydrophilic black carbon & 0.20 \\
Dust & 0.02 \\
\hline
\end{tabular}

sea ice. Surface melt primarily influences the SSL (of snow or ice, when snow-free conditions are present) but will modify the internal layer aerosol content if surface melt exceeds the SSL thickness. Analogously, basal melting primarily influences the interior ice layer unless this completely melts away. If all ice melts, then whatever aerosol mass is present within the sea ice is fluxed into the ocean.

As evident from Eq. (10), we assume that surface melting is subject to meltwater scavenging (i.e., meltwater removes only a fraction $S$ of the existing aerosol content in the melted volume) but that basal and lateral melting that occur primarily below the ocean waterline are not. The scavenging factors $S$ used for the different aerosol types follow Flanner et al. (2007) and are shown in Table 1 . If snow completely melts away, then any aerosol not scavenged with the meltwater remains on the ice surface in the ice SSL. There are numerous processes that affect the ice or snow mass and hence the mass mixing ratio $m_{\mathrm{ri}}$. In addition to the melt terms, these include sublimation, basal ice growth, and snowfall, which modify the concentration of aerosol within the snow and/or ice but not the total aerosol mass $m$.

After the aerosol mass content changes are applied following Eq. (10) for the SSL and internal layers, the aerosol content is vertically repartitioned. This allows for a fixed SSL thickness for the next time step as assumed by the radiative transfer scheme. For thin snow or sea ice, the SSL thickness decreases as in the radiation scheme.

In contrast to terrestrial snow cover, sea ice is in motion in response to winds and ocean currents. We treat the aerosol mass content as a conservative mass tracer such that

$$
\frac{d m_{i}}{d t}=-\nabla \cdot\left(m_{i} \mathbf{u}\right),
$$

where $\mathbf{u}$ is the ice velocity field computed from the model dynamics. As with the melt ponds [Eq. (7)], the aerosol mass content is transferred across ice categories as ice area shifts within the ITD because of ice growth, melt, and mechanical redistribution.

\section{Model experiments}

The CCSM4 model is described in Gent et al. (2011). To assess the influence of the new radiation physics on 
the sea ice model simulation and the coupled climate response, six integrations were performed. These use a coupled atmosphere-land-sea ice-slab ocean model configuration. The Community Atmosphere Model, version 4 (CAM4) is described by R. B. Neale et al. (2011, unpublished manuscript). Here we use the atmospheric model resolution of $2^{\circ}$. The land model is discussed in Lawrence et al. (2012). The sea ice model uses a nominally $1^{\circ}$ resolution with the northern pole smoothly displaced into Greenland. The slab ocean model (SOM) assumes a fixed depth ocean heat reservoir with lateral and vertical ocean heat transports prescribed using a fixed flux ("qflux") that is obtained from a coupled model simulation and is the same for all of our experiments. The SOM solves for ocean surface temperature based on this qflux and a calculated ocean surface heat exchange, which uses the same equations as the fully coupled model. The sea surface temperatures and sea ice conditions simulated by the SOM integrations compare very well to the results from the coupled simulation that was used to obtain the qflux. For more information on the SOM formulation, see Bitz et al. (2012). Although the SOM configuration excludes dynamical ocean feedbacks, which will be important for the transient climate response, it is less computationally expensive and quickly reaches an equilibrated state (after about $30 \mathrm{yr}$, compared to thousands of years for the fully coupled model). Integrations using this configuration are thus valuable for assessing the sea ice pond and aerosol influence on equilibrated conditions and for determining how these new model capabilities modify the surface albedo response in controlled experiments where only atmospheric $\mathrm{CO}_{2}$ concentrations are changed. All of the simulations were run for $60 \mathrm{yr}$, allowing us to compare equilibrated climatologies averaged from year 30 to year 60 for the different integrations.

The experiments include two sets of simulations (Table 3 ). The first uses a preindustrial $\mathrm{CO}_{2}$ level of $285 \mathrm{ppmv}$ (referred to as $1 \mathrm{XCO}_{2}$ ), and the second uses twice this value (referred to as $2 \mathrm{XCO}_{2}$ ). For each $\mathrm{CO}_{2}$ level, simulations were performed 1 ) with the full radiation package that includes melt ponds and aerosol deposition (control), 2 ) with aerosol deposition disabled but melt ponds active (No_A), and 3) with both aerosol deposition and melt ponds disabled (No_AP). The climate sensitivity obtained from the control simulations is discussed in Bitz et al. (2012). We primarily focus on the Arctic climate response, because this is where the impact of melt ponds and aerosol deposition is the largest. For averages, we consider an Arctic domain (referred to as Arctic mean) as used in previous work (e.g., Holland et al. 2010) and as shown on Fig. 2. This encompasses the total ocean (and sea ice) area poleward of $80^{\circ} \mathrm{N}$ between longitudes $117^{\circ} \mathrm{W}$ and $100^{\circ} \mathrm{E}$ and poleward of $68^{\circ} \mathrm{N}$ from $100^{\circ} \mathrm{E}$ to $117^{\circ} \mathrm{W}$. In the Antarctic, the sea ice is nearly pond free in all the simulations and aerosol contents in the ice and overlying snowpack are negligible. This is consistent with observations, which show very little pond coverage (Andreas and Ackley 1982) for Antarctic sea ice.

In the control simulations with the full radiation package, diagnostic calculations were included to compute the radiative forcing associated with the melt pond and aerosols. We define this surface sea ice shortwave radiative forcing $R_{\mathrm{SW}}$ as

$$
R_{\mathrm{SW}}=\mathrm{SW}_{A}-\mathrm{SW}_{X},
$$

where $\mathrm{SW}_{A}$ denotes the absorbed shortwave flux in sea ice for all surfaces and $\mathrm{SW}_{X}$ denotes the sea ice absorbed shortwave flux excluding either ponds or aerosols. This allows us to assess the enhanced shortwave absorption that results from the presence of the ponds or aerosols. Comparisons with experiments that exclude aerosols (No_A) and exclude both aerosols and ponds (No_AP) provide information on how feedbacks associated with the aerosol and/or pond forcing modify the direct radiative effects. The aerosol deposition used here is relevant for 1850 conditions and obtained from standalone CAM experiments with aerosol emissions based on observational reconstructions (Lamarque et al. 2010).

Finally, we discuss the aerosol and pond simulation in a twentieth-century CCSM4 control integration (Gent et al. 2011). This is a fully coupled atmosphere-ocean-sea iceland simulation with $1^{\circ}$ atmospheric resolution and nominally $1^{\circ}$ ocean and sea ice resolution. Aspects of the Arctic simulations from the set of twentieth-twenty-firstcentury integrations are discussed in de Boer et al. (2012) (for the atmosphere), Jahn et al. (2012) (sea ice and ocean), and Vavrus et al. (2012) (Arctic change). From this simulation, we diagnose how radiative forcing associated with ponds and aerosols changes in response to transient twentieth-century forcings.

\section{Radiative impacts in control integrations}

The Northern Hemisphere sea ice extent and Arctic ice thickness for the control integrations are shown in Fig. 2. For the $1 \mathrm{XCO}_{2}$ control, the ice is extensive and thick compared to present-day observations. This is in part due to preindustrial $\mathrm{CO}_{2}$ levels that are about $100 \mathrm{ppm}$ less than present conditions. Additionally, the sea ice thickness and extent are sensitive to atmospheric model resolution, and, as noted by Shields et al. (2012), Arctic sea ice is extensive in simulations with a $2^{\circ}$ atmosphere 
(a)

NH Ice Extent

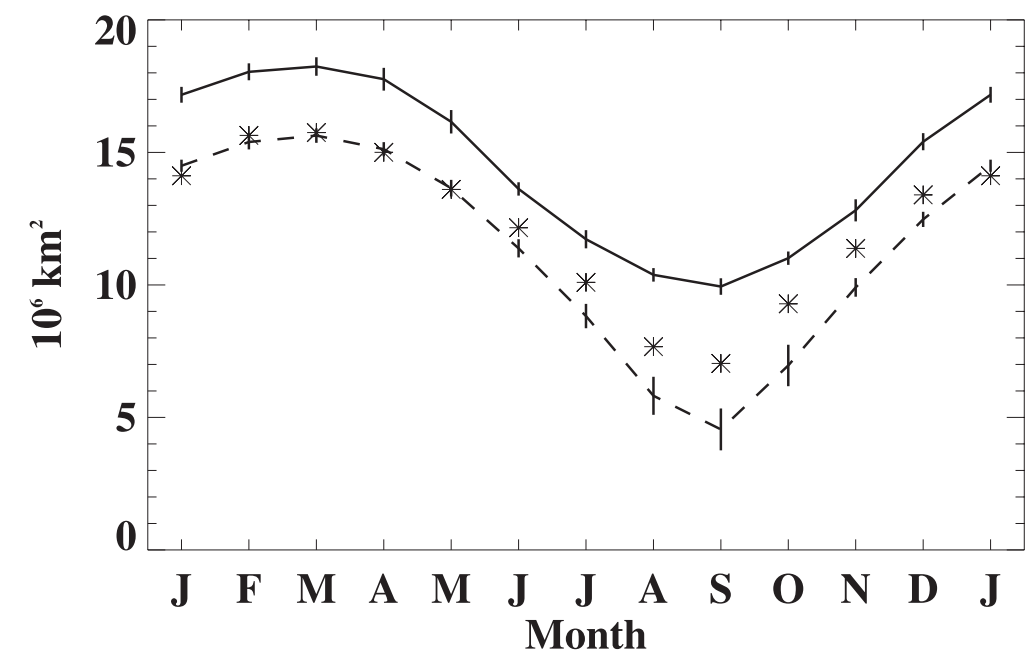

(b) Thickness 1XCO2

(c) Thickness 2XCO2
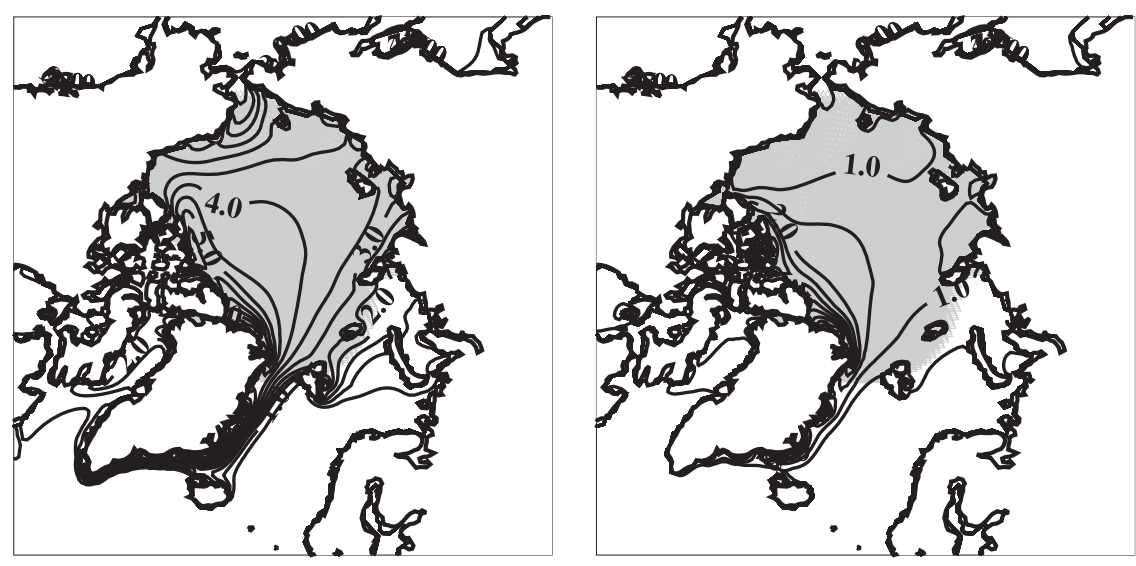

FIG. 2. (a) The annual cycle of Northern Hemisphere sea ice extent in $10^{6} \mathrm{~km}^{2}$. Annual ice thickness for the control integrations at (b) $1 \mathrm{XCO}_{2}$ and (c) $2 \mathrm{XCO}_{2}$. In (a), the observed ice extent averaged from 1979 to 2000 is shown by the asterisks (Fetterer et al. 2007), the solid line shows $1 \mathrm{XCO}_{2}$ simulation results, and the dashed line shows $2 \mathrm{XCO}_{2}$ simulation results. The contour interval is $0.5 \mathrm{~m}$ for ice thickness. Gray shading in (b),(c) show the region used in computing Arctic averages.

(compared to a $1^{\circ}$ atmosphere) because of different poleward heat transport. Given that we use the $2^{\circ}$ atmosphere here and that the specified ocean heat transport (qflux) is taken from an equivalent resolution coupled simulation, we would expect more fidelity to observations with a higher-resolution atmosphere (and associated qflux). In the $2 \mathrm{XCO}_{2}$ climate, the ice thins considerably and is less extensive. The two control equilibrium states bracket present-day observations for both extent and thickness, consistent with $\mathrm{CO}_{2}$ levels that also bracket present-day conditions.

Not surprisingly, the fractional coverage of surface ponding on Arctic sea ice is highly dependent on the atmospheric $\mathrm{CO}_{2}$ level (Fig. 3). In both climate states, pond formation is initiated in June when snowmelt begins. Pond areal coverage peaks in July or August, depending on the location, and then declines. On an Arctic mean, the maximum climatological monthly averaged pond cover reaches about $10 \%$ for the $1 \mathrm{XCO}_{2}$ climate in July and $30 \%$ for the $2 \mathrm{XCO}_{2}$ climate in August. The interannual variability in pond fraction is considerable, with July Arctic-mean values varying from $5 \%-18 \%$ for individual years from the $30 \mathrm{yr}$ analyzed from the $1 \mathrm{XCO}_{2}$ climate and $14 \%-39 \%$ for the $30 \mathrm{yr}$ analyzed from the $2 \mathrm{XCO}_{2}$ climate. Comparisons with observed pond statistics are difficult given that observational estimates are temporally 


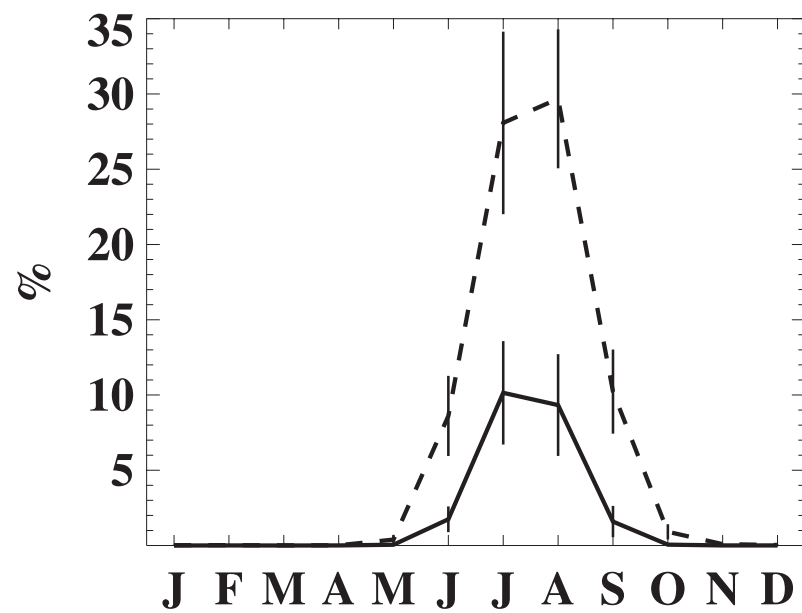

FIG. 3. The Arctic-averaged melt pond fraction annual cycle for the $1 \mathrm{XCO}_{2}$ (solid line) and $2 \mathrm{XCO}_{2}$ (dashed line) control simulations. Plus-minus one standard deviation for the $30 \mathrm{yr}$ of analyzed integration is shown by the vertical lines.

and spatially disparate. Additionally, the climate states simulated here are not directly comparable to present-day conditions because of the different $\mathrm{CO}_{2}$ levels and equilibrated conditions. Regardless of these caveats, the simulated pond cover is generally consistent with observed estimates that showed about $20 \%$ pond cover in the SHEBA field site vicinity from aerial photographs in August (Eicken et al. 2002; Perovich et al. 2002b).

The black carbon content of the snowpack over sea ice also shows reasonable values (Fig. 4). The black carbon content is generally larger in the $1 \mathrm{XCO}_{2}$ climate, which is consistent with less meltwater flushing from the snowpack. In the $1 \mathrm{XCO}_{2}$ climate, values in April range from a maximum in the Barents Sea of approximately $12 \mathrm{ngC} \mathrm{g}^{-1}$ regionally averaged to a minimum of $2.5 \mathrm{ngC} \mathrm{g}^{-1}$ regionally averaged over the Beaufort Sea. Recall that the prescribed aerosol deposition for both control integrations is identical and consistent with 1850 emissions. Thus, the emission sources used to obtain the prescribed deposition fluxes are largely natural and lower than for the present-day climate, and we expect the simulated aerosol content to be lower than observed. Black carbon observations in the Arctic sea ice and overlying snow cover are limited, but a recent survey (Doherty et al. 2010) showed a median value of $7 \mathrm{ngC} \mathrm{g}^{-1}$ for springtime Arctic Ocean surface snow samples. This varied spatially from lower values $\left(5 \mathrm{ngC} \mathrm{g}^{-1}\right)$ near the North Pole to higher values $\left(10 \mathrm{ngC} \mathrm{g}^{-1}\right)$ at lower Arctic Ocean latitudes. SHEBA observations show that the April snow cover had an average background black carbon content of about $4.4 \mathrm{ngC} \mathrm{g}^{-1}$ (Grenfell et al. 2002). These values are a bit higher but in the same general range as those simulated here. (a)
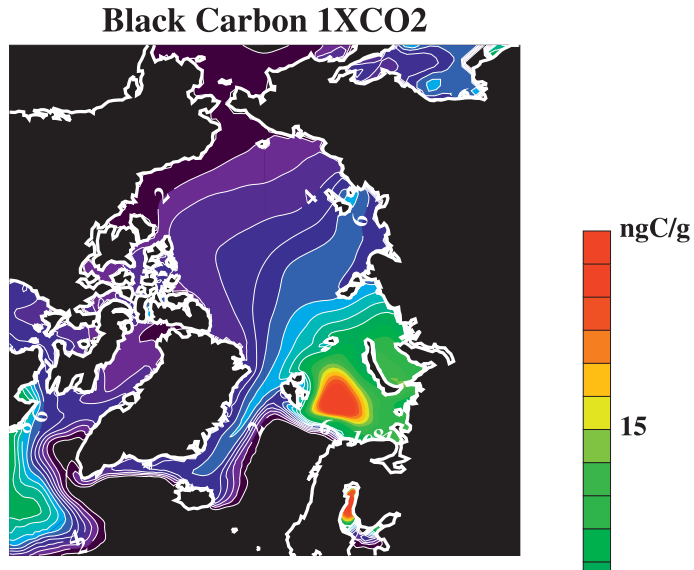

(b)

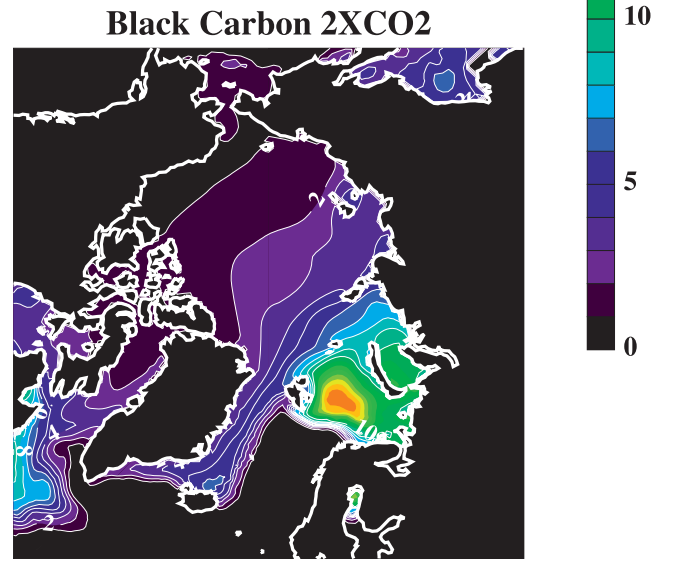

FIG. 4. The concentration of black carbon in the interior snowpack over sea ice in $\mathrm{ngC} \mathrm{g}^{-1}$ in April for the (a) $1 \mathrm{XCO}_{2}$ and (b) $2 \mathrm{XCO}_{2}$ control integrations.

The Arctic Ocean-averaged surface albedo (averaged over both ice covered and open water regions) is shown in Fig. 5 for the $1 \mathrm{XCO}_{2}$ and $2 \mathrm{XCO}_{2}$ control integrations. It reaches values greater than 0.8 during the spring snowcovered season and drops during the summer melt season as the ice becomes snow free and open water regions increase. For $2 \mathrm{XCO}_{2}$ conditions, the albedo is reduced to about 0.3 in August because of the large amount of open water present during the summer in this simulation.

Surface ponding reduces the surface albedo and enhances shortwave absorption in the sea ice. Figure 6 shows the enhanced sea ice shortwave absorption associated with the melt ponds with annual Arctic-mean values shown in Table 2. For an Arctic mean, the simulated melt ponds increase summer [June-August (JJA)] shortwave absorption in sea ice by an average of about 3 and $6 \mathrm{~W} \mathrm{~m}^{-2}$ for the $1 \mathrm{XCO}_{2}$ and $2 \mathrm{XCO}_{2}$ simulations, respectively with a peak in July of $5\left(1 \mathrm{XCO}_{2}\right)$ and $10 \mathrm{~W} \mathrm{~m}^{-2}\left(2 \mathrm{XCO}_{2}\right)$. The spatial pattern of this enhanced shortwave absorption is quite similar between the $1 \mathrm{XCO}_{2}$ (Figs. 6b,c) and $2 \mathrm{XCO}_{2}$ climates (Figs. 6d,e), although larger in the 


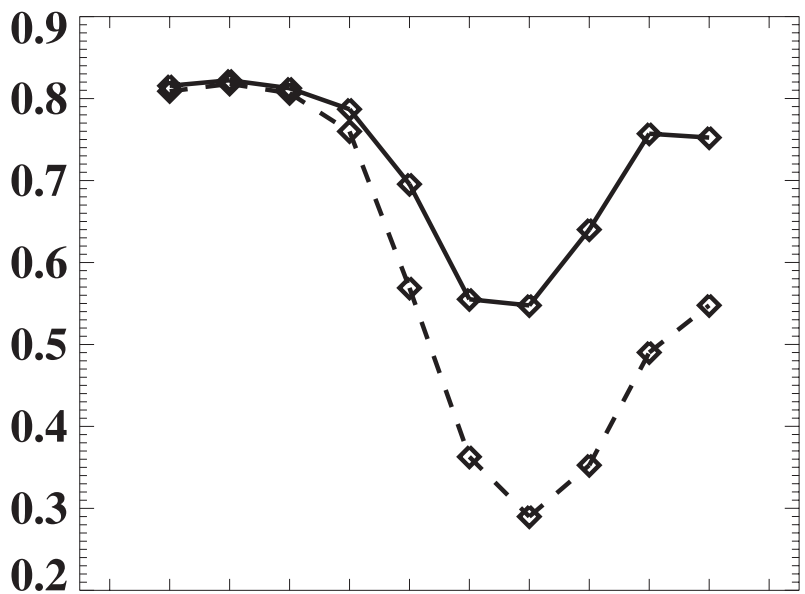

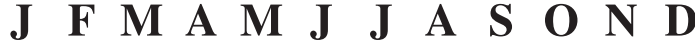 Month}

FIG. 5. The Arctic average surface albedo from the 1XCO2 (solid) and $2 \mathrm{XCO} 2$ (dash) control integrations.

$2 \mathrm{XCO}_{2}$ case. In the $1 \mathrm{XCO}_{2}$ climate, the enhanced absorption is isolated to the shelf regions in June and July because the central Arctic ice pack retains some snow cover throughout the year in the colder climate. In the $2 \mathrm{XCO}_{2}$ climate, the enhanced shortwave absorption is largest in the shelf regions in June as the snow cover melts away. During July, the enhanced absorption extends throughout the Arctic as the interior sea ice pack becomes snow free. The change in pond conditions and their radiative impacts for the $1 \mathrm{XCO}_{2}$ and $2 \mathrm{XCO}_{2}$ climates enhances the surface albedo response and hence modifies the surface albedo feedback.

Darkening the surface snow and ice cover by aerosol deposition also modifies the albedo and enhances absorption of solar radiation (Table 2). For the Arctic mean, this amounts to less than $1 \mathrm{~W} \mathrm{~m}^{-2}$ on a monthly average for both the $1 \mathrm{XCO}_{2}$ and $2 \mathrm{XCO}_{2}$ control simulations (Fig. 7). This aerosol impact peaks earlier in the summer (MayJune) than the pond influence, because aerosols accumulated over the fall-winter are partially flushed out with melting during the summer. In contrast to the pond forcing, the $1 \mathrm{XCO}_{2}$ aerosol forcing is larger than in the $2 \mathrm{XCO}_{2}$ climate because of smaller melt rates (and less meltwater flushing) and larger aerosol contents that remain throughout the summer. Although the Arctic-mean forcing is quite small, locally the forcing can be considerable, particularly in the Barents and Kara Seas where it can reach about $8 \mathrm{~W} \mathrm{~m}^{-2}$ in the $1 \mathrm{XCO}_{2}$ climate and about $3 \mathrm{~W} \mathrm{~m}^{-2}$ in the $2 \mathrm{XCO}_{2}$ climate at individual grid cells in June (Figs. $7 \mathrm{~b}, \mathrm{~d}$ ). As with the ponds, the different impacts of aerosols in different climate regimes suggest that aerosol deposition and cycling could modify the surface albedo feedback with impacts on the sea ice and climate response to forcing perturbations. Note that the aerosol deposition used here is consistent with 1850 conditions and is low compared to present-day values, a point that we will return to in section 6 .

In contrast to the Arctic, sea ice in the Antarctic shows little impact from ponds and aerosol deposition. The average pond fraction remains below $1 \%(3 \%)$ in the $1 \mathrm{XCO}_{2}$ $\left(2 \mathrm{XCO}_{2}\right)$ climate for all months and the aerosol contents are negligible. This causes a pond radiative forcing that is below $0.1 \mathrm{~W} \mathrm{~m}^{-2}$ for all months in the $2 \mathrm{XCO}_{2}$ integration (and considerably smaller than that for the $1 \mathrm{XCO}_{2}$ climate). The aerosol radiative forcing averaged for Antarctic sea ice remains below $0.005 \mathrm{~W} \mathrm{~m}^{-2}$ for all months.

\section{Influence of feedbacks on simulated response to melt ponds and aerosol deposition}

The Arctic-averaged annual radiative forcing associated with ponds and aerosols in the $1 \mathrm{XCO}_{2}$ control simulation is 0.9 and $0.2 \mathrm{~W} \mathrm{~m}^{-2}$, respectively (Table 2). Considering the latent heat of fusion, this combined energy equals a modest $0.11-\mathrm{m}$ annual ice melt. However, the ponds and aerosol deposition modify the surface albedo, which can trigger positive feedbacks. As such, their influence may be considerably larger than the direct radiative forcing would suggest. This has been noted before for aerosol forcing on snow cover (e.g., Hansen and Nazarenko 2004; Hansen et al. 2005; Flanner et al. 2007).

Here, we assess the influence of melt ponds and aerosol deposition on sea ice for the total climate response using simulations that exclude aerosol deposition (No_A) and simulations that exclude both ponds and aerosols (No_AP). These sensitivity simulations only affect the sea ice. Aerosol deposition over the land is unchanged. These simulations are performed for both $1 \mathrm{XCO}_{2}$ and $2 \mathrm{XCO}_{2}$ climates to investigate how the pond and aerosol forcing agents affect feedbacks and interact for different climate regimes.

\section{a. Influence on mean $1 \mathrm{XCO}_{2}$ climate}

The mean annual cycle of Arctic ice thickness and Northern Hemisphere ice area are shown in Fig. 8, and values that are significantly different from the control simulation at a $99 \%$ confidence level are indicated. Aerosol deposition on sea ice significantly reduces the annual-mean Arctic ice thickness by $0.3 \mathrm{~m}$ in the $1 \mathrm{XCO}_{2}$ climate and decreases the September ice area by $0.5 \times 10^{6} \mathrm{~km}^{2}$. Consistent with higher radiative forcing, the pond impacts are larger, accounting for a further 0.8 -m annual-mean thinning of the Arctic ice in the $1 \mathrm{XCO}_{2}$ simulations and a further reduction in September ice area of $0.9 \times 10^{6} \mathrm{~km}^{2}$. Overall, the presence of ponds and aerosol deposition on sea ice significantly reduces the Arctic-mean ice thickness by over $1 \mathrm{~m}$ and the Northern Hemisphere September ice area by 
(a)

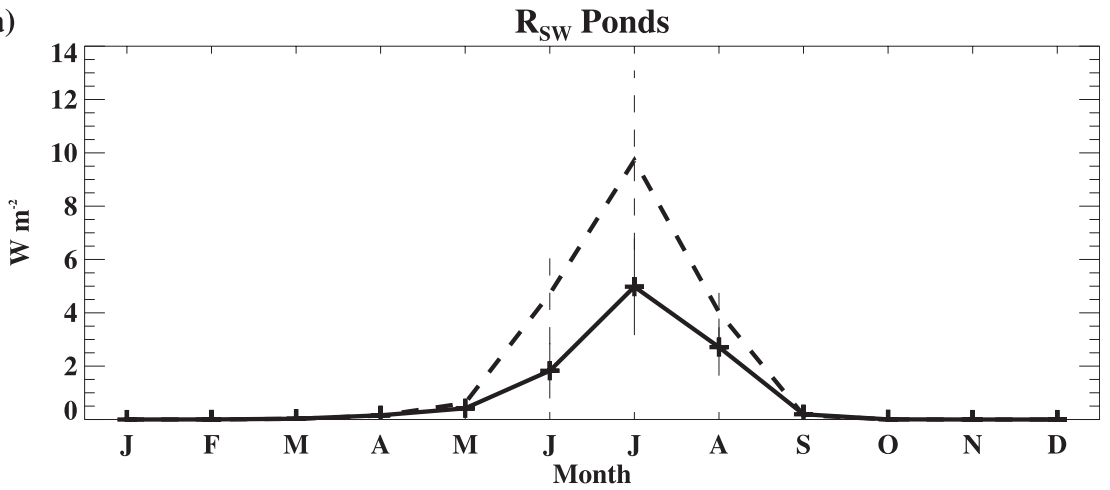

(b)

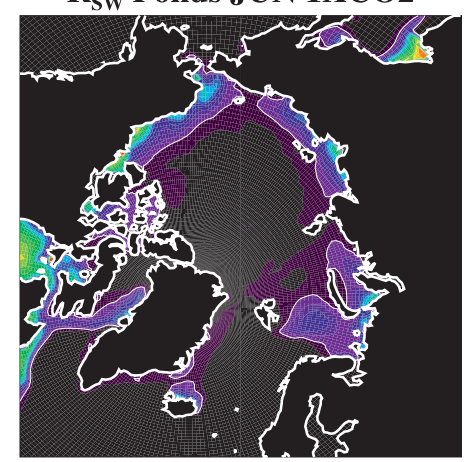

(d)

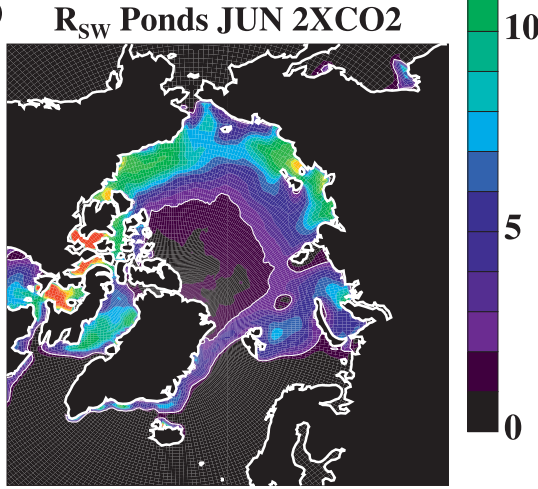

(c)

$\mathbf{R}_{\mathrm{SW}}$ Ponds JUL 1XCO2

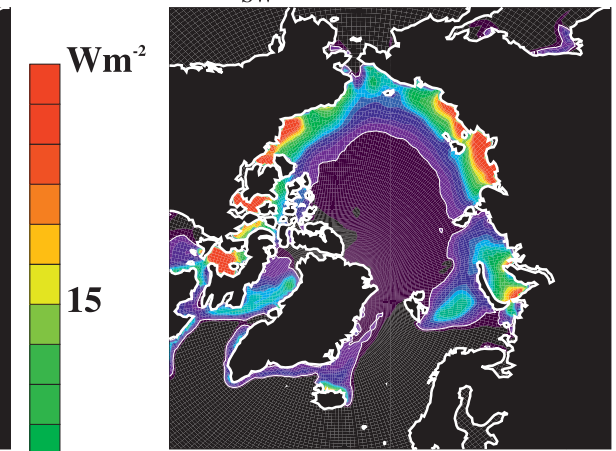

(e)
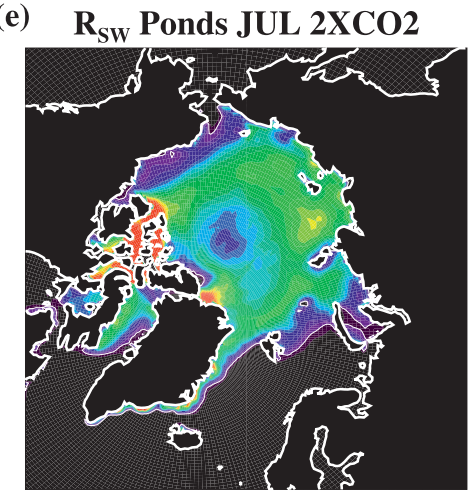

FIG. 6. The enhanced shortwave absorption in sea ice associated with the melt ponds in $\mathrm{W} \mathrm{m}{ }^{-2}$ for (a) the Arctic average (averaged over the entire region) for $1 \mathrm{XCO}_{2}$ (solid) and $2 \mathrm{XCO}_{2}$ (dash) control simulations (b) June and (c) July average from the $1 \mathrm{XCO}_{2}$ control simulation, and (d) June and (e) July average from the $2 \mathrm{XCO}_{2}$ control simulation. In (a), plusminus one standard deviation is shown by the vertical lines.

$1.4 \times 10^{6} \mathrm{~km}^{2}$ in the $1 \mathrm{XCO}_{2}$ climate. This is considerably larger than the $0.11 \mathrm{~m}$ of enhanced melting suggested by the aerosol and pond radiative forcing, indicating that positive feedbacks are activated. Indeed the enhanced shortwave absorption in sea ice in the $1 \mathrm{XCO}_{2}$ control simulation compared to the simulation that excludes ponds and aerosols is $5.2 \mathrm{~W} \mathrm{~m}^{-2}$ for the JJA average, which is much larger than the direct radiative effects of the ponds and aerosols discussed in section 4 .

The ice mass budgets for the integrations are shown in Table 3 . When ponds and aerosols are active, surface ice melt increases by only $0.02 \mathrm{~m} \mathrm{yr}^{-1}$. However, the basal melting of sea ice increases by about $60 \%$, an equivalent of $0.16 \mathrm{~m} \mathrm{yr}^{-1}$. This highlights how changes in the radiative forcing (and surface albedo) associated with ponds and aerosols initiate a feedback that contributes to more summer open water formation, larger open water absorption, and enhanced basal melting. The increased summer melting is balanced by a larger basal ice growth and smaller ice divergence (net transport) from the Arctic, resulting in a larger-amplitude annual cycle. Increased winter growth results from larger conductive fluxes through the thinner 
TABLE 2. The annual Arctic average radiative forcing due to ponds and aerosols in $\mathrm{W} \mathrm{m}^{-2}$.

\begin{tabular}{lcc}
\hline \hline & $\begin{array}{c}\text { Aerosol radiative } \\
\text { forcing }\end{array}$ & $\begin{array}{c}\text { Pond radiative } \\
\text { forcing }\end{array}$ \\
\hline Control $1 \mathrm{XCO}_{2}$ & 0.2 & 0.9 \\
Control $2 \mathrm{XCO}_{2}$ & 0.1 & 1.6 \\
\hline
\end{tabular}

ice pack, which gives rise to the nonlinear dependence of ice thickness on ice growth (Bitz and Roe 2004). Consistent with this is a larger surface heat loss to the atmosphere, and the annual-mean $70^{\circ}-90^{\circ} \mathrm{N}$ surface air temperature (not shown) is $1.4^{\circ} \mathrm{C}$ warmer in the $1 \mathrm{XCO}_{2}$ control simulation than in the No_AP simulation. Other atmospheric changes are also expected because of the different surface heat exchange.

\section{b. Influence on climate response to $\mathrm{CO}_{2}$ doubling}

In assessing the different climate response to $\mathrm{CO}_{2}$ doubling in our experiments, both the direct effects of ponds and aerosols and differences in the mean $1 \mathrm{XCO}_{2}$ climate states must be considered. Figure 9 shows the Arctic-averaged ice thickness response to $\mathrm{CO}_{2}$ doubling for the three sets of simulations for both the absolute (Fig. 9c) and fractional (Fig. 9d) change. The control simulation thins by $2.3 \mathrm{~m}$ in the $2 \mathrm{XCO}_{2}$ climate. The

(a)

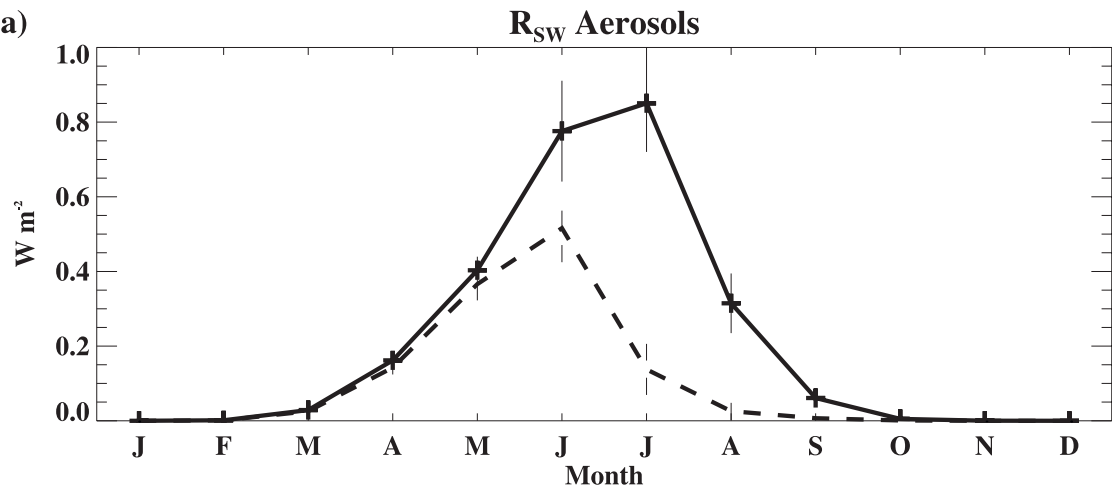

(b)

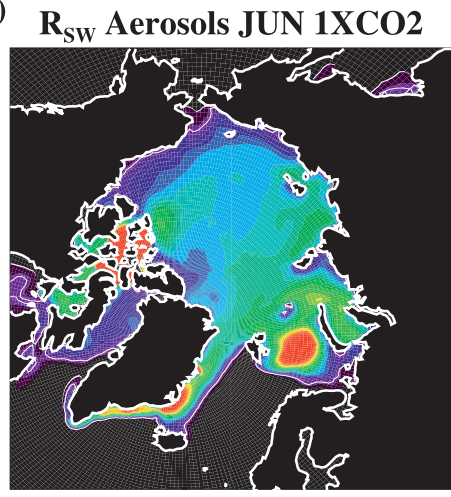

(d)

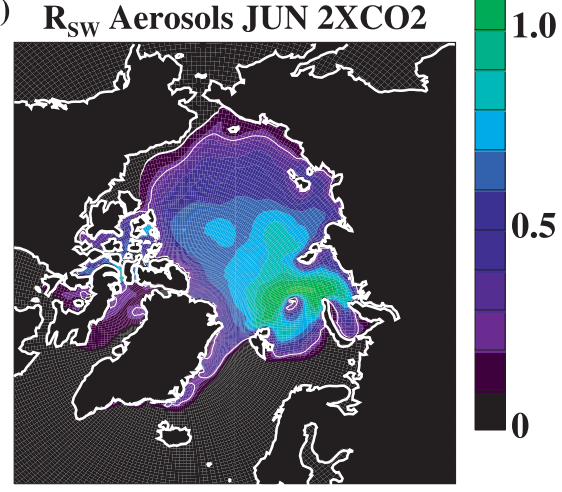

(c) $\mathbf{R}_{\mathrm{SW}}$ Aerosols JUL 1XCO2

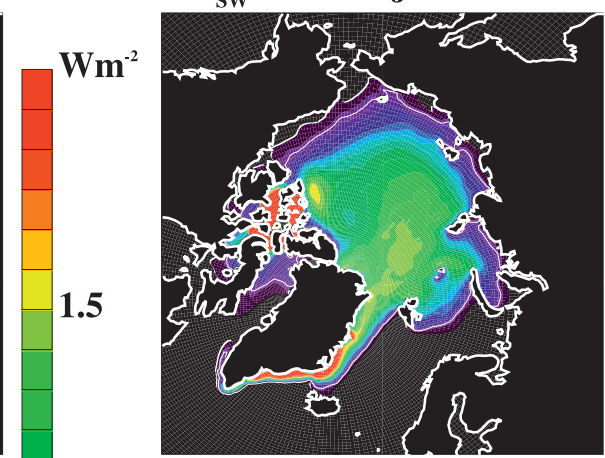

(e) $\mathbf{R}_{\mathrm{SW}}$ Aerosols JUL 2XCO2

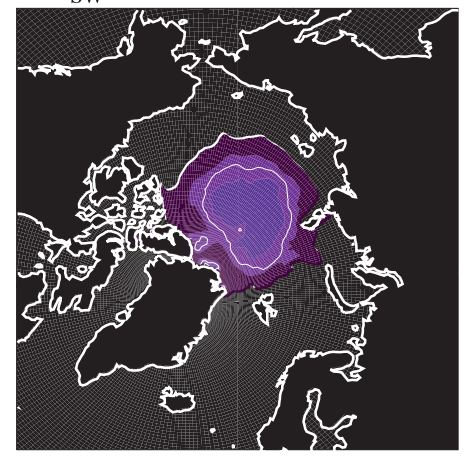

FIG. 7. As in Fig. 6, but associated with aerosols. 
(a) $\mathrm{NH}$ Ice Area 1XCO2

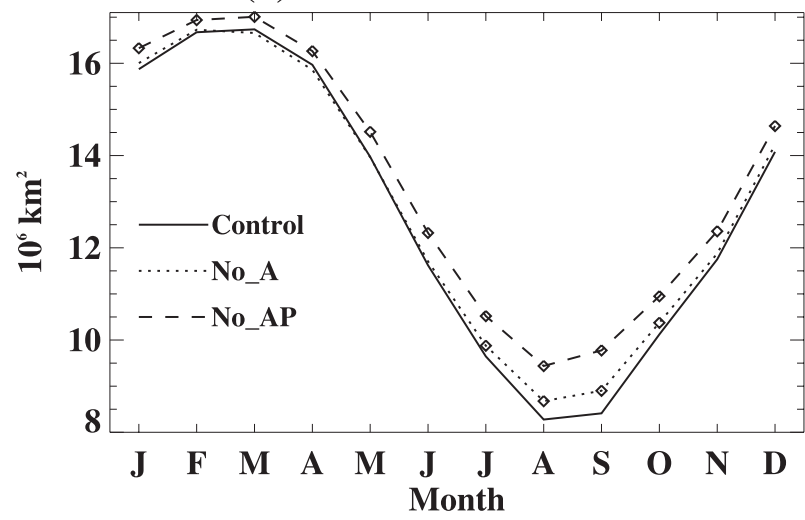

(b) Arctic Ice Thickness 1XCO2

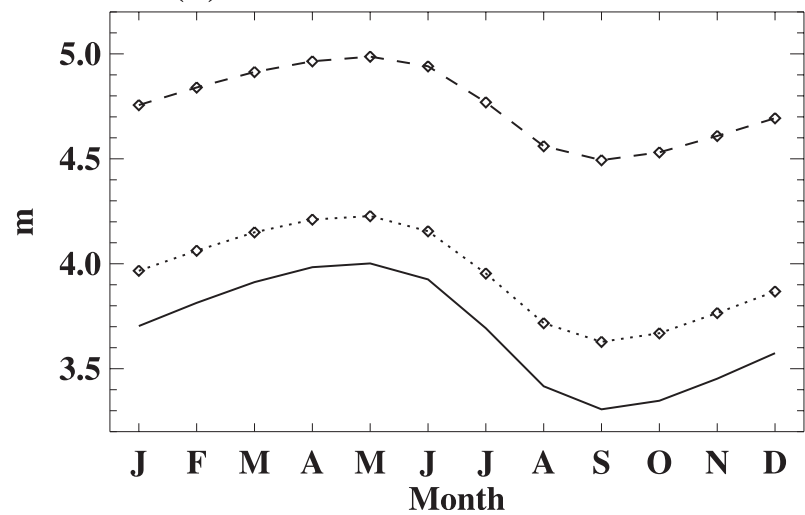

FIG. 8. The mean annual cycle of (a) Northern Hemisphere ice area in millions of square kilometers and (b) Arctic-averaged ice thickness in meters for the control simulation (solid), the simulation that excludes aerosols (No_A; dotted), and the simulation that excludes aerosols and melt ponds (No_AP; dashed). All simulations shown use $1 \mathrm{XCO}_{2}$ forcing. Changes from the control simulation that are significant at a $99 \%$ confidence level are denoted by diamonds.

simulations that exclude aerosols and ponds have a larger ice volume loss of 2.6 (No_A) and 2.9 m (No_AP). This significantly different thickness response is influenced by the mean state, and, consistent with previous studies (Holland et al. 2010), larger thinning occurs in models with initially thicker sea ice. However, when considering the ice thickness change as a fraction of the initial state (Fig. 9d), the simulation with ponds has a significantly larger summer ice thickness response. Similarly, the Northern Hemisphere ice area response across the integrations (Figs. 9a,b) shows a significantly larger fractional ice area response in integrations that include melt ponds. This is consistent with increased ponding, particularly in the vulnerable shelf regions in the $2 \mathrm{XCO}_{2}$ climate, and suggests that the presence of ponds may amplify the surface albedo feedback and the ice thickness and area response.
TABLE 3. Arctic average sea ice mass budgets for the integrations in meters per year. The relatively small terms of lateral ice melt and frazil ice formation are not shown and account for the imbalance in the net budget terms shown here.

\begin{tabular}{lcccc}
\hline \hline & $\begin{array}{c}\text { Surface } \\
\text { melt }\end{array}$ & $\begin{array}{c}\text { Basal } \\
\text { melt }\end{array}$ & $\begin{array}{c}\text { Basal } \\
\text { growth }\end{array}$ & Divergence \\
\hline Control $1 \mathrm{XCO}_{2}$ & 0.18 & 0.41 & 1.04 & 0.48 \\
No_A $1 \mathrm{XCO}_{2}$ & 0.14 & 0.36 & 0.96 & 0.48 \\
No_AP $1 \mathrm{XCO}_{2}$ & 0.16 & 0.25 & 0.94 & 0.54 \\
Control $2 \mathrm{XCO}_{2}$ & 0.32 & 0.84 & 1.29 & 0.18 \\
No_A 2XCO & 0.30 & 0.81 & 1.30 & 0.23 \\
No_AP $2 \mathrm{XCO}_{2}$ & 0.37 & 0.64 & 1.22 & 0.24 \\
\hline
\end{tabular}

This is further supported by an analysis of surface albedo changes across the experiments. The surface albedo change is strongly related to ice area change, which is largest in the control run partly as a consequence of the thinner mean $1 \mathrm{XCO}_{2}$ sea ice. To mitigate the influence of the different mean states, we consider the surface albedo change as a function of ice concentration change (Fig. 10). For regions with the same ice concentration change, the control experiment with active ponds and aerosols has smaller reductions in surface albedo than in the No_A simulation where aerosols are excluded (particularly in July). This indicates that aerosols on sea ice decrease the albedo change in the $2 \mathrm{xCO}_{2}$ climate and reduce the strength of the albedo feedback. This is consistent with a larger melt out of aerosols in the warmer climate, which effectively brightens the surface and counteracts other climate-induced sea ice surface changes (e.g., reduced snow). In the absence of changes in aerosol deposition, climate-induced changes in aerosol meltout appear to reduce the strength of the surface albedo feedback. In contrast, comparisons of the control and No_AP simulations indicate a larger albedo reduction (particularly in August) when both ponds and aerosols are active. Because this is not due to the direct aerosol influence, it can be attributed to melt pond effects and suggests that the simulation of enhanced pond cover in a warmer climate enhances the surface albedo change and leads to a stronger surface albedo feedback.

\section{Aerosol and pond effects in a fully coupled twentieth-century integration}

The standard CCSM4 twentieth-century fully coupled integrations (Gent et al. 2011) prescribe changes in external forcing, including greenhouse gas concentrations, volcanic aerosols, and solar variability at the top of the atmosphere based on observational records and chemical transport models. A time-varying aerosol deposition is also specified based on historical simulations that use the CCSM chemistry component (Lamarque et al. 2010). As 
(a) $\mathrm{NH}$ Ice Area 2XCO2-1XCO2

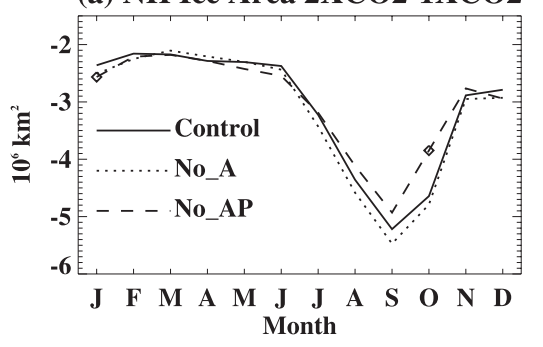

(c) Arctic Thickness 2XCO2-1XCO2

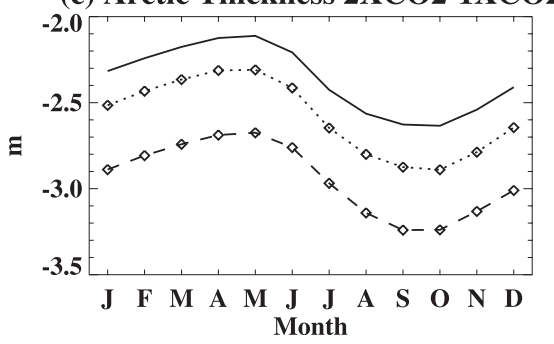

(b) NH Ice Area 2XCO2-1XCO2

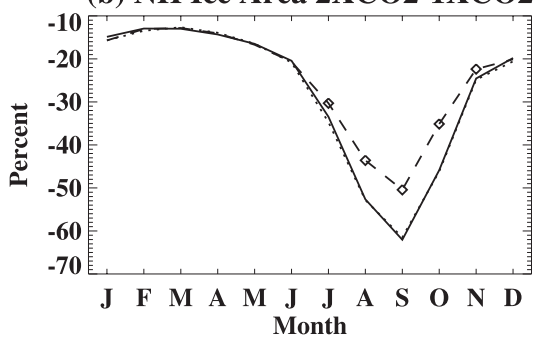

(d) Arctic Thickness 2XCO2-1XCO2

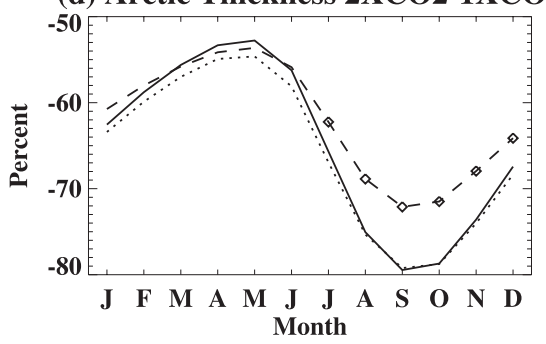

FIG. 9. The response to $\mathrm{CO}_{2}$ doubling of Northern Hemisphere ice area in (a) millions of square kilometers and (b) percent of the $1 \mathrm{XCO}_{2}$ state as well as Arctic-averaged ice thickness in (c) meters and (d) percent of the $1 \mathrm{XCO}_{2}$ state for the three sets of integrations (control simulation $=$ solid, No_A $=$ dotted, and No_AP $=$ dashed $)$. Simulated responses that are significantly different than the control response (at a $99 \%$ confidence level) are denoted by diamonds.

discussed by Jahn et al. (2012), the Arctic sea ice in CCSM4 twentieth-century simulations compares very well to observations in its areal extent, mean thickness and spatial pattern, and variability and trends in the late twentieth century. Here, we discuss the radiative forcing associated with ponds and aerosols in the sea ice system and their changes over a transient twentieth-century simulation. This complements the above analysis, which assessed equilibrated conditions and indicates whether aerosol and pond forcing agents may contribute to latetwentieth-century Arctic sea ice decline.

Over the twentieth-century simulations, the black carbon aerosol deposition on Arctic sea ice generally increases (not shown). This contributes to an increased concentration of black carbon in the snowpack over sea ice, particularly from 1850 to 1910 , where it increases from about 4 to $7.4 \mathrm{ngC} \mathrm{g}^{-1}$ (Fig. 11). After 1910, the simulated black carbon content in the snow cover over Arctic sea ice varies from about 6 to $8 \mathrm{ngC} \mathrm{g}^{-1}$ on interdecadal time scales. This is generally consistent with the limited observed values of black carbon content over Arctic sea ice (e.g., Grenfell et al. 2002; Doherty et al. 2010). However, it disagrees with long-term records from Greenland ice cores (McConnell et al. 2007), which show black carbon content peaking in 1910 and then declining rapidly until nearly stabilizing around 1950. This is likely related to different source regions for the black carbon deposition over Greenland and over the Arctic sea ice (e.g., Koch and Hansen 2005). As noted by Lamarque et al. (2010), simulated time series of West Greenland black carbon deposition (not shown) that are used here do generally agree with the ice-core data, showing a peak around 1915 and a following rapid decline to about 1960.

Temporal variations of black carbon content are due to a combination of changes in deposition and climatedriven meltout. Over the late twentieth century, increased surface melting enhances flushing of aerosols and contributes to the relatively stable black carbon concentrations even while the Arctic deposition is increasing. Because dust deposition shows little increases over the twentieth century, its content in the Arctic snowpack over sea ice generally decreases because of increased meltwater flushing (not shown).

Melt ponding over the ice pack increases over the twentieth century as more surface ice melt and longer melt seasons are realized. This results in an Arctic-mean pond fraction of about $20 \% \pm 7 \%$ for the 1985-2005 August mean, a $7 \%$ increase from the $1850-70$ values. In the late twentieth century, simulated ponding occurs over most of the Arctic basin, although it remains largest in the shelf regions.

The Arctic-mean radiative forcing associated with ponds and aerosols in sea ice over the twentieth-century simulation is shown in Fig. 12. The aerosol radiative forcing is generally $0.5-1.0 \mathrm{~W} \mathrm{~m}^{-2}$ during June and July, which is comparable to the values shown in Flanner et al. (2007) for 
(a) July

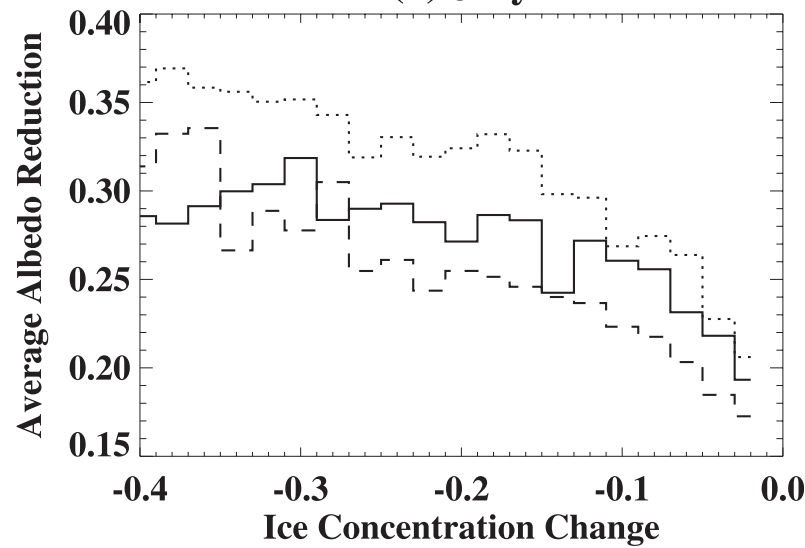

(b) August

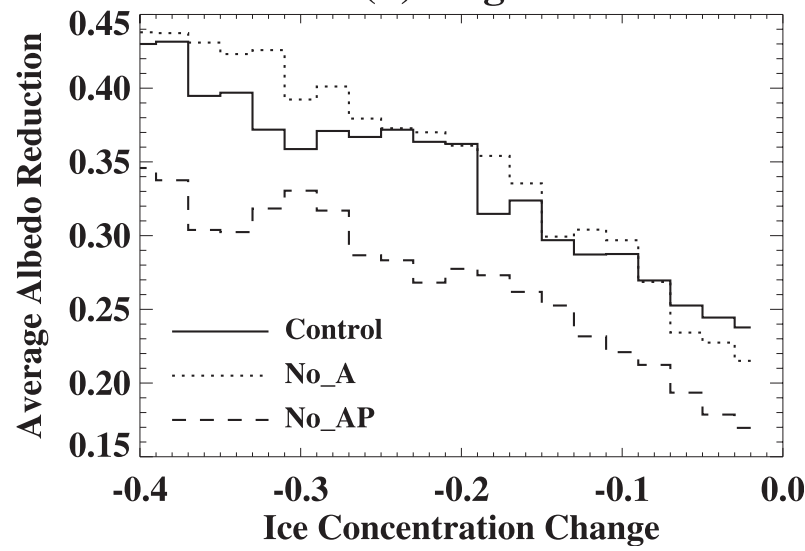

FIG. 10. The change in surface albedo vs the change in ice concentration for (a) July and (b) August for the $2 \mathrm{XCO}_{2}-1 \mathrm{XCO}_{2}$ climates in the three sets of integrations (control = solid, No_A = dotted, and No_AP $=$ dashed). The averages are performed for the common region where the initial $\left(1 \mathrm{XCO}_{2}\right)$ monthly ice concentration is greater than 0.8 in all of the experiments.

individual years. It increases over the twentieth century and shifts to earlier in the season. Although it is a relatively small forcing, it occurs during the transition from snow covered to snow-free sea ice. As such, it may contribute to earlier melt season onset dates that are realized over the twentieth century. This has important implications for the albedo feedback as the reduction in albedo from snow covered to ponded ice is considerable (e.g., Perovich et al. 2002a) and occurs at the height of solar input. The melt pond radiative forcing also increases over the twentieth century (Fig. 12b) as the pond fractions increase, reaching about $10 \mathrm{~W} \mathrm{~m}^{-2}$ in July for the 1985-2005 average. Clearly, both ponds and aerosols contribute to increased ice melt and enhanced sea ice loss over the twentieth century. Because they both influence the ice-albedo feedback, their effect on the climate state is sure to be larger than the direct radiative forcing implies.

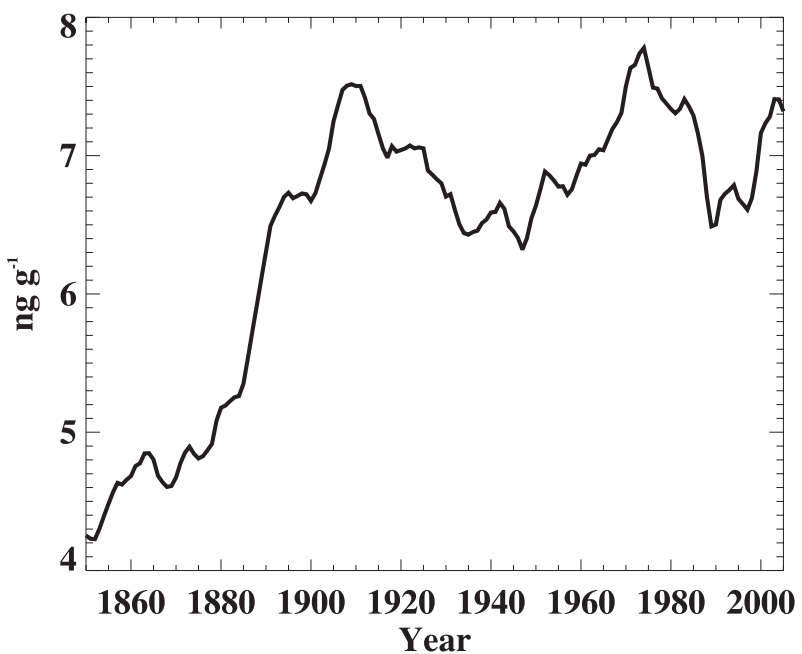

FIG. 11. The Arctic-averaged concentration of black carbon $\left(\mathrm{ng} \mathrm{g} \mathrm{g}^{-1}\right)$ in the interior snowpack over sea ice for the twentiethcentury integration.

\section{Conclusions}

We have documented new features of the sea ice component of the Community Climate System Model, version 4 (CCSM4). We focus on the new shortwave radiation scheme and new capabilities that this allows, because these are arguably the most notable changes in the sea ice model and have not been discussed previously. The new radiative transfer scheme (BL07) makes use of inherent optical properties to define the scattering and absorption for snow, sea ice, and included absorbers. This allows for new physically consistent capabilities in the model, including a parameterization of aerosol deposition and cycling within sea ice and parameterized melt ponds that relate pond formation to surface melting. These new capabilities have important consequences for the simulation of the surface albedo feedback and are a fundamental advance in representing a more realistic, complete, and physically based sea ice albedo.

To diagnose the influence of these new parameterizations on the CCSM4 climate, simulations were performed with the atmosphere-land-sea ice-slab ocean model version of CCSM4. The pond fraction and aerosol content simulated in these integrations were quite reasonable and comparable to observed values. In control $1 \mathrm{XCO}_{2}$ integrations with ponds and aerosols active in the sea ice model, we determined that aerosols enhance shortwave absorption in sea ice by $0.2 \mathrm{~W} \mathrm{~m}^{-2}$ for an annual Arctic mean. Melt ponds contribute an additional $0.9 \mathrm{~W} \mathrm{~m}^{-2}$ enhanced absorption. The numbers are considerably larger when considering a regional perspective. Aerosols account for up to $8 \mathrm{~W} \mathrm{~m}^{-2}$ of enhanced absorption in regions of the Barents and Kara Seas in June. The pond 
(a)

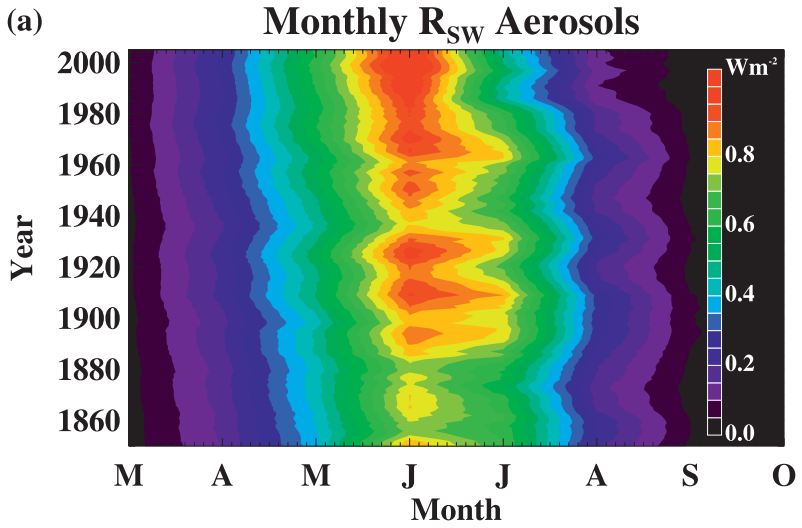

(b)

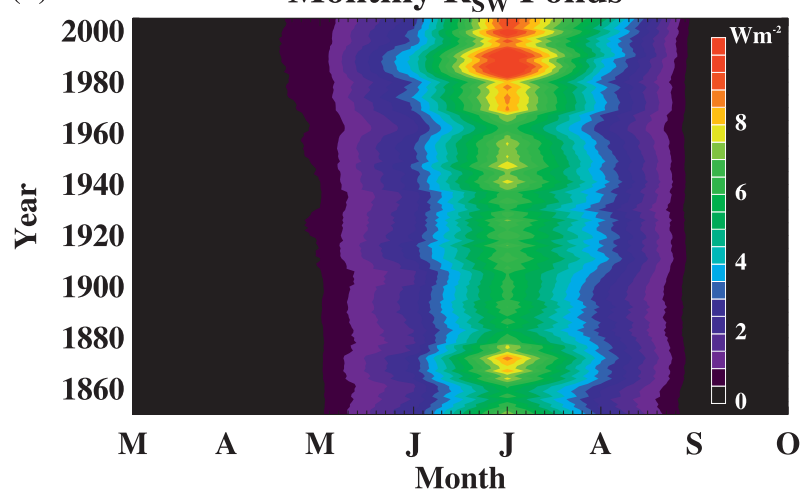

FIG. 12. The Arctic monthly averaged shortwave radiative forcing in $\mathrm{W} \mathrm{m}^{-2}$ associated with (a) aerosols and (b) melt ponds in sea ice for the twentieth-century simulation. Note the different color scale for (a),(b).

forcing is localized to Arctic shelf regions in the $1 \mathrm{XCO}_{2}$ climate, reaching over $10 \mathrm{~W} \mathrm{~m}^{-2}$ in July.

The direct radiative effects of ponds and aerosols are influenced by the mean climate state. For simulations with $2 \mathrm{XCO}_{2}$ levels, the aerosol radiative forcing is considerably smaller and peaks a month earlier compared to the $1 \mathrm{XCO}_{2}$ simulation. Both simulations applied the same prescribed aerosol deposition, and the change in forcing was related to an enhanced meltout of aerosols in the warmer $2 \mathrm{XCO}_{2}$ climate. In contrast, pond forcing increased in the $2 \mathrm{XCO}_{2}$ climate, reaching about $10 \mathrm{~W} \mathrm{~m}^{-2}$ for the July Arctic mean (compared to $5 \mathrm{~W} \mathrm{~m}^{-2}$ for the $1 \mathrm{XCO}_{2}$ simulation). The pond influence was also more widespread in the warmer climate as larger surface melting enhanced melt pond coverage throughout the basin. The changing direct radiative effects of ponds and aerosols in a changing climate point to the importance of these capabilities for more accurately simulating the surface albedo feedback.

Although the direct radiative effects of the ponds and aerosols are quite small, they do modify the surface albedo and thus induce the positive surface albedo feedback. As confirmed by simulations that exclude pond and aerosol effects, their influence is thus considerably larger than the direct radiative effects would imply. When ponds and aerosols are excluded, the simulated annual-mean Arctic sea ice for the $1 \mathrm{XCO}_{2}$ climate is over $1 \mathrm{~m}$ thicker. Pond effects account for about $70 \%$ of this response and aerosol deposition effects account for the remaining $30 \%$. This influences the Northern Hemisphere summer sea ice area, which is $1.4 \times 10^{6} \mathrm{~km}^{2}$ larger in September when ponds and aerosol deposition are suppressed. This is considerably larger than the difference implied by the direct radiative forcing and is realized by different sea ice mass budgets, which modify the ice-ocean-atmosphere exchange. Additionally, comparisons of the climate response to a doubling of $\mathrm{CO}_{2}$ in integrations with and without active ponds and aerosols suggest that ponds enhance the surface albedo feedback and aerosols in sea ice reduce the feedback (when aerosol deposition remains constant). Thus, these new model capabilities have the potential to influence the climate response to forcing perturbations.

Finally, we have diagnosed the pond and aerosol radiative forcing in a transient twentieth-century simulation of the fully coupled CCSM4 (Gent et al. 2011). Changes in the pond and aerosol radiative forcing of sea ice result from and contribute to the changing climate state. A time-varying aerosol deposition also directly influences the aerosol content in sea ice and overlying snow. Overall, we find that the sea ice radiative forcing associated with aerosols is relatively small but increases over the twentieth century because of enhanced deposition, which is larger than enhanced meltout of the aerosols. It also shifts to earlier in the season, which may play a role in an earlier simulated melt onset that is realized over the twentieth century. The radiative forcing of ponds also increases over the twentieth century as more surface melting contributes to a larger pond fraction. In general, the changing climate state has important implications for the magnitude and timing of the radiative forcing associated with ponds and aerosols. Over the twentieth century, simulated changes in these properties reduce the surface sea ice albedo, contribute to increased melting, and may play a role in the late-twentieth-century Arctic sea ice trends. Further experiments testing the effects of these agents are required to quantify these impacts.

Although the new sea ice model capabilities discussed here represent an important step forward in more realistically simulating the sea ice albedo and associated feedbacks, there remain limitations that should be considered in future model developments. For example, Flanner et al. (2007) showed that there are important interactions between black carbon deposition and snow aging that effectively increases the influence of aerosols 
in snow. Although the snow grain radius does increase in our model as the surface temperature reaches melting, a sophisticated snow aging parameterization (with a resulting increase in snow grain radius) is not included and is required to fully realize these aerosol-snow interactions. Additionally, liquid meltwater or the scavenged aerosol content within it is not able to remain within the snowpack in the current model but instead is flushed out to the ocean. In reality, some of this water can remain within the snowpack and change its optical properties. There are also potential limitations of including only two vertical reservoirs of aerosol content in the snow (and two in the sea ice). Finally, the melt pond parameterization discussed here is simple and only affects the surface albedo. Future efforts should incorporate the latent heat effects of ponds, which can have important implications for the timing of fall freezeup.

Acknowledgments. We thank the large community of scientists who contribute to the development of CCSM. We thank Steve Warren and two anonymous reviewers for constructive comments that improved our manuscript. MMH acknowledges support through NSF Grants OPP-0902068 and OPP-0902065. DAB was supported under NSF Grant OPP-0908675. ECH acknowledges funding from the Biological and Environmental Research division of the U.S. Department of Energy Office of Science; Los Alamos National Laboratory is operated by the National Nuclear Security Administration of the U.S. Department of Energy under Contract DE-AC5206NA25396. BL acknowledges support for this work through the NSF Climate Dynamics Program SGER Grant ATM-0454311.

The CESM project is supported by the National Science Foundation and the Office of Science (BER) of the U.S. Department of Energy. Computing resources were provided by the Climate Simulation Laboratory at NCAR's Computational and Information Systems Laboratory (CISL), which is sponsored by the National Science Foundation and other agencies. This research was enabled by CISL compute and storage resources. Bluefire, a 4064-processor IBM Power6 resource with a peak of 77 TeraFLOPS provided more than 7.5 million computing hours, the GLADE high-speed disk resources provided 0.4 petabytes of dedicated disk, and CISL's 12-PB HPSS archive provided over 1 petabyte of storage in support of this research project.

\section{REFERENCES}

Andreas, E. L, and S. F. Ackley, 1982: On the differences in ablation seasons of Arctic and Antarctic sea ice. J. Atmos. Sci., 39, 440-447.
Bitz, C. M., and W. H. Lipscomb, 1999: An energy-conserving thermodynamic sea ice model for climate study. J. Geophys. Res., 104, 15 669-15 677.

- and G. H. Roe, 2004: A mechanism for the high rate of sea ice thinning in the Arctic Ocean. J. Climate, 17, 3623-3632.

K. Shell, P. Gent, D. Bailey, G. Danabasoglu, K. Armour, M. Holland, and J. Kiehl, 2012: Climate sensitivity of the Community Climate System Model, version 4. J. Climate, in press.

Boe, J., A. Hall, and X. Qu, 2009: September sea-ice cover in the Arctic Ocean projected to vanish by 2100 . Nat. Geosci., 2, 341343, doi:10.1038/ngeo467.

Brandt, R. E., S. G. Warren, A. P. Worby, and T. C. Grenfell, 2005: Surface albedo of the Antarctic sea ice zone. J. Climate, 18, 3606-3622.

Briegleb, B. P., and B. Light, 2007: A delta-Eddington multiple scattering parameterization for solar radiation in the sea ice component of the Community Climate System Model. NCAR Tech. Note TN-472+STR, 100 pp.

—, C. M. Bitz, E. C. Hunke, W. H. Lipscomb, M. M. Holland, J. L. Schramm, and R. E. Moritz, 2004: Scientific description of the sea ice component in the Community Climate System Model, version three. NCAR Tech. Note NCAR/TN-463_STR, $70 \mathrm{pp}$.

Curry, J. A., J. L. Schramm, D. K. Perovich, and J. O. Pinto, 2001: Applications of SHEBA/FIRE data to evaluation of snow/ice albedo parameterizations. J. Geophys. Res., 106 (D14), 15 34515355 .

de Boer, G., W. Chapman, J. E. Kay, B. Medeiros, M. D. Shupe, S. Vavrus, and J. Walsh, 2012: A characterization of the presentday Arctic atmosphere in CCSM4. J. Climate, in press.

Doherty, S. J., S. G. Warren, T. C. Grenfell, A. D. Clarke, and R. E. Brandt, 2010: Light-absorbing impurities in Arctic snow. Atmos. Chem. Phys., 10, 11 647-11 680, doi:10.5194/acp-1011647-2010.

Ebert, E. E., and J. A. Curry, 1993: An intermediate one-dimensional thermodynamic sea ice model for investigating ice-atmosphere interactions. J. Geophys. Res., 98, 10 085-10 109.

Eicken, H., H. R. Krouse, D. Kadko, and D. K. Perovich, 2002: Tracer studies of pathways and rates of meltwater transport through Arctic summer sea ice. J. Geophys. Res., 107, 8046, doi:10.1029/2000JC000583.

Fetterer, F., and N. Untersteiner, 1998: Observations of melt ponds on Arctic sea ice. J. Geophys. Res., 103, 24 821-24 835.

— K. Knowles, W. Meier, and M. Savoie, 2007: Sea ice index. National Snow and Ice Data Center, Boulder, CO, digital media. [Available online at http://nsidc.org/data/g02135.html.]

Flanner, M. G., C. S. Zender, J. T. Randerson, and P. J. Rasch, 2007: Present-day climate forcing and response from black carbon in snow. J. Geophys. Res., 112, D11202, doi:10.1029/ 2006JD008003.

, _ _ , P. G. Hess, N. M. Mahowald, T. H. Painter, V. Ramanathan, and P. J. Rasch, 2009: Springtime warming and reduced snow cover from carbonaceous particles. Atmos. Chem. Phys., 9, 2481-2497.

Flocco, D., and D. L. Feltham, 2007: A continuum model of melt pond evolution on Arctic sea ice. J. Geophys. Res., 112, C08016, doi:10.1029/2006JC003836.

$\longrightarrow,-$, and A. K. Turner, 2010: Incorporation of a physically based melt pond scheme into the sea ice component of a climate model. J. Geophys. Res., 115, C08012, doi:10.1029/ 2009JC005568.

Gent, P. R., and Coauthors, 2011: The Community Climate System Model, version 4. J. Climate, 24, 4973-4991. 
Grenfell, T. C., and S. G. Warren, 1999: Representation of a nonspherical ice particle by a collection of independent spheres for scattering and absorption of radiation. J. Geophys. Res., 104 (D24), 31 697-31 709.

- B. Light, and M. Sturm, 2002: Spatial distribution and radiative effects of soot in the snow and sea ice during the SHEBA experiment. J. Geophys. Res., 107, 8032, doi:10.1029/ 2000JC000414.

Hall, A., 2004: The role of surface albedo feedback in climate. J. Climate, 17, 1550-1568.

Hansen, J., and L. Nazarenko, 2004: Soot climate forcing via snow and ice albedos. Proc. Natl. Acad. Sci. USA, 101, 423-428.

_ , and Coauthors, 2005: Efficacy of climate forcings. J. Geophys. Res., 110, D18104, doi:10.1029/2005JD005776.

Holland, M. M., and C. M. Bitz, 2003: Polar amplification of climate change in coupled models. Climate Dyn., 21, 221-232, doi:10.1007/ s00382-003-0332-6.

,-- , and B. Tremblay, 2006: Future abrupt reductions in the summer Arctic sea ice. Geophys. Res. Lett., 33, L23503, doi:10.1029/2006GL028024.

— M. C. Serreze, and J. Stroeve, 2010: The sea ice mass budget of the Arctic and its future change as simulated by coupled climate models. Climate Dyn., 34, 185-200, doi:10.1007/ s00382-008-0493-4.

Hunke, E. C., and J. K. Dukowicz, 2002: The elastic-viscousplastic sea ice dynamics model in general orthogonal curvilinear coordinates on a sphere-Incorporation of metric terms. Mon. Wea. Rev., 130, 1848-1865.

— model, documentation and software, version 4.0. Los Alamos National Laboratory Tech. Rep. LA-CC-06-012, 76 pp.

Jahn, A., and Coauthors, 2012: Late twentieth-century simulation of Arctic sea ice and ocean properties in CCSM4. J. Climate, 25, 1431-1452.

Jordan, R. E., E. L Andreas, and A. P. Makshtas, 1999: Heat budget of snow-covered sea ice at North Pole 4. J. Geophys. Res., 104, 7785-7806.

Koch, C., and J. Hansen, 2005: Distant origins of Arctic black carbon: A Goddard Institute for Space Studies ModelE experiment. J. Geophys. Res., 110, D04204, doi:10.1029/ 2004JD005296.

Lamarque, J.-F., and Coauthors, 2010: Historical (1850-2000) gridded anthropogenic and biomass burning emissions of reactive gases and aerosols: Methodology and application. Atmos. Chem. Phys., 10, 7017-7039, doi:10.5194/acp-10-70172010.

Lawrence, D. M., K. W. Oleson, M. G. Flanner, C. G. Fletcher, P. J. Lawrence, S. Levis, S. C. Swenson, and G. B. Bonan, 2012: The CCSM4 land simulation, 1850-2005: Assessment of surface climate and new capabilities. J. Climate, in press.

Light, B., T. C. Grenfell, and D. K. Perovich, 2008: Transmission and absorption of solar radiation by Arctic sea ice during the melt season. J. Geophys. Res., 113, C03023, doi:10.1029/ 2006JC003977.

Lipscomb, W. H., 2001: Remapping the thickness distribution in sea ice models. J. Geophys. Res., 106, 13 989-14000.

- , and E. C. Hunke, 2004: Modeling sea ice transport using incremental remapping. Mon. Wea. Rev., 132, 1341-1354.

_, _ _ W. Maslowski, and J. Jakacki, 2007: Ridging, strength, and stability in high-resolution sea ice models. J. Geophys. Res., 112, C03S91, doi:10.1029/2005JC003355.
Manabe, S., and R. J. Stouffer, 1980: Sensitivity of a global climate model to an increase of $\mathrm{CO}_{2}$ concentration in the atmosphere. J. Geophys. Res., 85, 5529-5554.

McConnell, J. R., and Coauthors, 2007: 20th century industrial black carbon emissions altered Arctic climate forcing. Science, 317, 1381-1384.

Oleson, K. W., and Coauthors, 2010: Technical description of version 4.0 of the Community Land Model (CLM). NCAR Tech. Note NCAR/TN-478+STR, 257 pp.

Pedersen, C. A., E. Roeckner, M. Lüthje, and J.-G. Winther, 2009: A new sea ice albedo scheme including melt ponds for ECHAM5 general circulation model. J. Geophys. Res., 114, D08101, doi:10.1029/2008JD010440.

Perovich, D. K., T. C. Grenfell, B. Light, and P. V. Hobbs, 2002a: Seasonal evolution of the albedo of multiyear Arctic sea ice. J. Geophys. Res., 107, 8044, doi:10.1029/2000JC000438.

_ W. B. Tucker III, and K. A. Ligett, 2002b: Aerial observations of the evolution of ice surface conditions during summer. J. Geophys. Res., 107, 8048, doi:10.1029/2000JC000449.

_ T. C. Grenfell, J. A. Richter-Menge, B. Light, W. B. Tucker III, and H. Eicken, 2003: Thin and thinner: Sea ice mass balance measurements during SHEBA. J. Geophys. Res., 108, 8050, doi:10.1029/2001JC001079.

Rothrock, D. A., 1975: The energetics of the plastic deformation of pack ice by ridging. J. Geophys. Res., 80, 4514-4519.

Schramm, J. L., M. M. Holland, J. A. Curry, and E. E. Ebert, 1997: Modeling the thermodynamics of a sea ice thickness distribution 1 . Sensitivity to ice thickness resolution. J. Geophys. Res., 102, 23 079-23 091.

Serreze, M. C., M. M. Holland, and J. Stroeve, 2007: Perspectives on the Arctic's shrinking sea-ice cover. Science, 315, 1533-1536.

Shields, C. A., D. A. Bailey, G. Danabasoglu, M. Jochum, J. T. Kiehl, S. Levis, and S. Park, 2012: The low-resolution CCSM4. J. Climate, in press.

Skyllingstad, E. D., and C. A. Paulson, 2007: A numerical study of melt ponds. J. Geophys. Res., 112, C08015, doi:10.1029/ 2006JC003729.

Solomon, S., D. Qin, M. Manning, M. Marquis, K. Averyt, M. M. B. Tignor, H. L. Miller Jr., and Z. Chen, Eds., 2007: Climate Change 2007: The Physical Science Basis. Cambridge University Press, 996 pp.

Thorndike, A. S., D. A. Rothrock, G. A. Maykut, and R. Colony, 1975: The thickness distribution of sea ice. J. Geophys. Res., 80, 4501-4513.

Tschudi, M. A., J. A. Curry, and J. A. Maslanik, 2001: Airborne observations of summertime surface features and their effect on surface albedo during SHEBA. J. Geophys. Res., 106 (D14), 15 335-15 344.

_ J. A. Maslanik, and D. K. Perovich, 2008: Derivation of melt pond coverage on Arctic sea ice using MODIS observations. Remote Sens. Environ., 112, 2605-2614.

Vavrus, S. J., M. M. Holland, A. Jahn, D. A. Bailey, and B. A. Blazey, 2012: Twenty-first-century Arctic climate change in CCSM4. J. Climate, in press.

Wang, M., and J. E. Overland, 2009: A sea ice free summer Arctic within 30 years? Geophys. Res. Lett., 36, L07502, doi:10.1029/ 2009GL037820.

Yackel, J. J., and D. G. Barber, 2000: Melt ponds on sea ice in the Canadian Archipelago 2. On the use of RADARSAT-1 synthetic aperture radar for geophysical inversion. J. Geophys. Res., 105 (C9), 22 061-22 070. 